\title{
Los proyectos de integración megarregional de China: el caso de la iniciativa Cinturón y Ruta (CYR)*
}

\section{The China's mega-Regional Integration Projects: the Case of the Belt and Road (B\&R) Initiative}

\section{Manuel de Jesús Rocha Pino**}

\begin{abstract}
SUMARIO: I. Introducción. II. Los acuerdos megarregionales como formuladores de normas del sistema multilateral de comercio. III. La política exterior de China durante el gobierno de Xi Jinping: la Iniciativa Cinturón y Ruta. IV. La trayectoria del proyecto Cinturón y Ruta (2013-2016). V. Las características y objetivos básicos del CYR. VI. El CYR y la gobernanza del sistema mundial de comercio. VII. La proyección geopolítica del Cinturón Económico de la Ruta de la Seda y la Ruta de la Seda Marítima del Siglo XXI. VIII. El CYR ¿un bien público global?. IX. Consideración final. X. Bibliografía mínima.
\end{abstract}

* La presente investigación se realizó mediante una beca de Estancia Postdoctoral otorgada por el Consejo Nacional de Ciencia y Tecnología de México (Conacyt).

** Doctor en Relaciones Internacionales e Integración Europea por el Departamento de Derecho Público y Ciencias Histórico-Jurídicas de la Universidad Autónoma de Barcelona. Actualmente es investigador postdoctoral en el Centro de Estudios de Asia y África de El Colegio de México. El autor agradece la asesoría de la doctora Marisela Connelly y los comentarios de dos dictaminadores anónimos; todos los errores y omisiones corresponden al autor. 
RESUMEN: En la investigación se considera que los acuerdos megarregionales de libre comercio pueden convertirse en instrumentos de las grandes potencias para incidir en la generación de la nueva normatividad del comercio global. En la primera parte del trabajo se analiza el origen de los acuerdos megarregionales (especialmente en los casos del TPP y el TTIP) y sus características generales. En la segunda parte de la investigación, se describen las características de un proyecto de integración megarregional de China: la Iniciativa Cinturón y Ruta (CYR). Se analiza el alcance geopolítico y geoeconómico del CYR, su importancia para el proceso de reforma económica en China y la relevancia del CYR para la gobernanza del sistema mundial de comercio.

Palabras clave: acuerdos megarregionales de libre comercio, Cinturón y Ruta, Organización Mundial de Comercio, inversión en infraestructura, conectividad.

ABSTRACT: This research considers that the mega-regional free trade agreements could become the great powers instruments to influence the generation of new norms for global trade. The first part of the research analyzes the origin of the mega-regional free trade agreements (especially the TPP and TTIP) and its general characteristics. The second part of the research analyzes the characteristics of the China's mega-regional integration project: the Belt and Road (B\&R) initiative. It analyzes the geopolitical and geo-economics scope of B\&R, its importance for the China's economic reform process and the $B \& R^{\prime}$ s relevance for the global trade governance.

Key words: mega-regional free trade agreements, Belt and Road, World Trade Organization, infrastructure investment, connectivity.

RÉSUMÉ: Ce travail de recherche part du principe que les accords de libre-échange méga-régionaux peuvent devenir les instruments des grandes puissances leur permettant d'avoir un impact sur la génération de la nouvelle normativité du commerce global. Dans la première partie, l’origine des accords méga-régionaux (en particulier, le Partenariat Trans-Pacifique (TPP) et le TTIP) est analysée tout comme leurs caractéristiques générales. Et dans la seconde partie du travail de recherche, les caractéristiques d'un projet d'intégration méga-régional chinois dénommé «La Ceinture et La Route» sont à leur tour examinées : la portée géopolitique et géoéconomique du projet, son importance dans le processus de réforme économique en Chine et sa pertinence dans la gouvernance du système commercial mondial.

Mots-clés: accords méga-régionaux de libre-échange, La Ceinture et La Route; Organisation mondiale du commerce, investissement dans les infrastructures, connectivité. 
Esta revista forma parte del acervo de la Biblioteca Jurídica Virtual del Instituto de Investigaciones Jurídicas de la UNAM

\section{INTRODUCCIÓN}

La investigación analiza el proyecto de integración megarregional impulsado por la República Popular China (en adelante, China) denominado Cinturón y Ruta (CYR - yidai-yilu, 一带一路). Esta iniciativa formulada por el gobierno de Xi Jinping en 2013 se basa en un amplio proyecto para la construcción de infraestructuras, esencialmente en el espacio euroasiático y en la cuenca del Océano Índico. El CYR puede considerarse una iniciativa de integración megarregional impulsada por China aunque con ciertas características específicas.

La iniciativa CYR ha coincidido en el tiempo con otros proyectos de integración megarregional, en especial los patrocinados por Estados Unidos en el caso del Acuerdo Estratégico Transpacífico de Asociación Económica y la Asociación Transatlántica de Comercio e Inversiones (esta última conjuntamente con la Unión Europea [UE]). La investigación se divide en dos partes. En la primera parte del trabajo se describe la trayectoria que han mantenido los procesos de negociación de los principales tratados megarregionales de libre comercio de la actualidad. Posteriormente, se analizan los intereses y objetivos de las potencias mundiales que tienen como prioridad el impulso de los acuerdos megarregionales: en el ensayo se enfatiza que una de las prioridades de los acuerdos megarregionales es incidir en la estructuración de una nueva normatividad para el sistema mundial de comercio. Finalmente, se analizan las consecuencias de dichos acuerdos para la gobernanza del sistema mundial de comercio y para los países que no han sido incluidos en las negociaciones de algún acuerdo megarregional.

En la segunda parte del ensayo, se analiza cómo el CYR es la respuesta de China para enfrentar su exclusión de algunos acuerdos megarregionales. El CYR se divide en dos componentes: el Cinturón Económico de la Ruta de la Seda (CERS) y la Ruta de la Seda Marítima del Siglo XXI (RSM-XXI).

Como una introducción al análisis del CYR, se hace una descripción de la política exterior instrumentada por el gobierno de Xi Jinping a partir de 2012. En segundo lugar, se analizan la trayectoria institucional, las características y los objetivos básicos del CYR, estableciendo una relación entre la agenda de la reforma económica en China con los objetivos actuales de la política exterior del gobierno chino. En el ámbito de la política exterior, 
el objetivo básico del CYR se orienta a superar el déficit en infraestructura presente en los países asiáticos en general y así facilitar los flujos comerciales y la conectividad entre China y los países europeos.

En tercer lugar, se analiza la relación entre el CYR y la gobernanza del sistema mundial de comercio actual (en especial la relación pragmática que puede establecerse entre las directivas del CYR y la normas de la Organización Mundial de Comercio). En el ensayo se señala que el gobierno chino tiene la aspiración de transformar al CYR en un proceso de integración regional al crear las suficientes condiciones de conectividad física y de interdependencia económica de manera previa a la negociación de un tratado de liberación comercial. Como fuentes primarias relacionadas con el CYR, en la investigación se analiza el documento Visión y Acciones sobre el Cinturón Económico de la Ruta de la Seda y la Ruta de la Seda Marítima del Siglo XXI, además de algunos discursos y declaraciones formulados por funcionarios chinos de alto nivel: se considera que dicho documento, hasta el momento, contiene las directivas básicas del CYR.

\section{LOS ACUERDOS MEGARREGIONALES COMO FORMULADORES DE NORMAS DEL SISTEMA MULTILATERAL DE COMERCIO}

\section{Definición y trayectoria de los acuerdos megarregionales de libre comercio}

Uno de los antecedentes de tipo institucional que explica el surgimiento de los proyectos de integración megarregional ha sido la inefectividad de los organismos multilaterales que han tratado de ejercer una gobernanza sobre los efectos de la crisis económica mundial, iniciada durante el periodo 2007-2008, como el G-20 o la Organización Mundial de Comercio (OMC). Otro antecedente, de tipo geopolítico, ha sido la reacción de las potencias occidentales a una mayor presencia económica y política de los países emergentes como los pertenecientes al grupo BRICS. ${ }^{1}$

Los acuerdos de libre comercio megarregional se pueden definir a partir de tres características: 1) por el número y el tamaño de las economías involucradas, que en todos los casos representan proporciones importantes del

1 Brasil, Rusia, India, China y Sudáfrica. 
Esta revista forma parte del acervo de la Biblioteca Jurídica Virtual del Instituto de Investigaciones Jurídicas de la UNAM

producto, la población, el comercio y la inversión extranjera directa mundiales; 2) los proyectos de integración megarregional buscan crear espacios económicos integrados de vasto alcance (ya sean euroasiáticos, transatlánticos o transpacíficos); 3) la agenda temática de los acuerdos incluye áreas no abordadas por los acuerdos de la OMC ni por otros acuerdos previos. Por esta razón, uno de los orígenes de los acuerdos megarregionales puede relacionarse con la paralización de la Ronda Doha de la OMC. ${ }^{2}$

Como mencionan Roberto Bouzas y Julieta Zelicovich sobre las consecuencias de la poca efectividad de las negociaciones de la Ronda Doha: ${ }^{3}$

La sumatoria de estas transformaciones y la ausencia de resultados sustantivos en la Ronda de Doha después de más de una década de negociaciones abrió la puerta a un período de generalizado pesimismo sobre la eficacia y la funcionalidad del régimen multilateral. En los últimos años este pesimismo se reforzó con la idea de que la propia agenda de negociaciones acordada en Doha ya se había vuelto obsoleta y crecientemente irrelevante frente a los "temas comerciales del futuro". ${ }^{4}$

Además de superar las barreras al comercio representadas por la paralización de las negociaciones de la Ronda Doha, la negociación de los acuerdos megarregionales tienen el objetivo de liberalizar a un conjunto de sectores pertenecientes a las denominadas agenda OMC-plus y OMC-extra como: ${ }^{5}$

2 Rosales, Osvaldo et al., "Las negociaciones megarregionales: hacia una nueva gobernanza del comercio mundial”, Serie Comercio Internacional, núm. 121, Santiago de Chile, CEPAL, 2013, pp. 7 y 8.

3 Bouzas, Roberto y Zelicovich, Julieta, "La Organización Mundial de Comercio, los acuerdos mega-regionales y los usos estratégicos del regionalismo”, Estudios de Economía Aplicada, vol.32, núm. 3, 2014, p. 968.

4 Ibidem, p. 969.

5 Zabalo, Patxi, “La Asociación Transatlántica de Comercio e Inversión en su contexto”, Boletín de Recursos de Información, núm. 41, Bilbao, Centro de Documentación Hegoa, Universidad del País Vasco, 2014, p. 2, disponible en: http: / / publicaciones.hegoa.ehu.es/assets/pdfs / 326 / Boletin_n\%C2\%BA41.pdf?1420642454 (fecha de consulta: 10 de marzo de 2016).

La agenda OMC-plus incluye áreas como: la liberalización del comercio internacional de servicios y los temas de derechos de la propiedad intelectual. La agenda OMC-extra incluye áreas como: la liberalización y protección de la inversión extranjera, la apertura de las compras del sector público a las empresas extranjeras y la política de competencia. Ibidem, p. 3.

También véase: Elliot, Kimberly, "How Much «Mega» in the Mega-RegionalTPP and TTIP: Implications for Developing Countries”, CGD Policy Paper 079, Washington, Center for Global Development, 2016, p. 5. 
Esta revista forma parte del acervo de la Biblioteca Jurídica Virtual del Instituto de Investigaciones Jurídicas de la UNAM

la armonización regulatoria de los aranceles y del comercio electrónico, los estándares laborales y la protección del ambiente así como la protección de las inversiones extranjeras mediante instrumentos como los Mecanismos de Arbitraje Inversionista-Estado (Investor-to-State Dispute Settlement-ISDS, por sus siglas en inglés) y las compras del sector público. ${ }^{6}$

De acuerdo con Stéphane Callens y Sofiane Cherfi, en la actualidad la tendencia en el desarrollo de las iniciativas de integración megarregional se caracteriza por el intenso flujo de las relaciones comerciales en tres espacios geoeconómicos en particular, así como por el volumen de sus flujos comerciales. Los tres espacios que sobresalen en la economía mundial se pueden definir como: transpacífico, euroasiático y transatlántico. ${ }^{7}$ En la actualidad, sobresalen cuatro proyectos de integración megarregional:

1) En el espacio transpacífico se ha conformado el Acuerdo Estratégico Transpacífico de Asociación Económica (TPP, por sus siglas en inglés) creado en 2015 y que entrará en vigor en $2017 .{ }^{8}$

6 Benvenisti, Eyal, "Democracy Captured:The Mega-Regional Agreements and the Future of Global Public Law”, IILJWorking Paper 2016/2, Nueva York, Institute for International Law and Justice, New York University School of Law, 2016, p. 3, disponible en: https: / wp.nyu. edu/megareg/wp-content/uploads/sites/3134/2016/03/Benvenisti_IILJ-MegaReg_2016-2.pdf (fecha de consulta: 2 de junio de 2016).

Otros sectores sujetos a negociación en los acuerdos megarregionales, con la finalidad de alcanzar una armonización regulatoria, han sido: los dispositivos médicos, los servicios profesionales, pesticidas, información y comunicación tecnológica, los productos farmacéuticos, textiles, vehículos, una mejor regulación de la protección a la propiedad intelectual, y el establecimiento de límites a las empresas de propiedad estatal. Idem.

7 Callens, Stéphane y Cherfi, Sofiane, "The Intensive Exchanges Flow: About a "New Regionalism”: OBOR (“One Belt, One Road”)", en Proceedings of the 9th International Management Conference "Management and Innovation For Competitive Advantage, Bucarest, 5 al 6 de noviembre de 2015, pp. 496 y 497.

8 Los antecedentes del TPP se remiten a los intentos de algunos países por superar la paralización de la Ronda de Doha, en este caso en el contexto de las actividades de algunos miembros del Foro Económico de Asia-Pacífico (APEC) para “encontrar vías por las que avance la cooperación regional y/o la liberalización económica global...”. Uno de estos trabajos realizados en el contexto de la APEC fue el acuerdo celebrado en 2002 entre los dirigentes de Chile, Nueva Zelanda y Singapur para conformar un grupo de "relaciones económicas más estrechas" (durante una reunión realizada en la Cumbre de la APEC llevada a cabo en Los Cabos, México). Brunei se agregó al grupo de trabajo en abril de 2005 conformándose entonces la Trans-pacific Economic Strategic Partnership (llamada también P-4): en junio de 2005 se concluyó el Acuerdo de Asociación Transpacífica que entró en vigor en julio de 2006 para 
2) En el espacio transatlántico, Estados Unidos y la UE han mantenido un proceso de negociación para acordar la Asociación Transatlántica de Comercio e Inversiones (TTIP, por sus siglas en inglés), proceso todavía inconcluso hasta el segundo semestre de 2016. ${ }^{9}$

De acuerdo con Marise Cremona, el TTIP debe considerarse el acuerdo más importante de la nueva generación de los denominados "Acuerdos Preferenciales de Nueva Generación" que han sido negociados por la UE desde 2006. Para Cremona, el TTIP está diseñado para "ir más allá de los compromisos existentes de la OMC", en especial en relación con los servicios, la cooperación regulatoria, las compras del

Singapur y Nueva Zelanda y en noviembre de 2006 para Brunei y Chile. En enero de 2009, el gobierno de los Estados Unidos anunció su intención de establecer negociaciones para formar parte del P-4 y en 2010 iniciaron las negociaciones formales para el ingreso de los Estados Unidos al grupo (además, en ese momento otros países también anunciaron sus intenciones para formar parte de la Asociación P-4: Australia, Malasia, Perú y Vietnam). Posteriormente, en octubre de 2010, Canadá y México “se agregaron formalmente a las negociaciones"; Japón fue el último país en formar parte a partir de 2012. La primera ronda de negociación delTPP tuvo lugar en julio de 2013 en Malasia y el acuerdo fue concluido en Atlanta en octubre de 2015.

Véase Anguiano Roch, Eugenio, "El Acuerdo Transpacífico: una visión geopolítica”, en Oropeza García, Arturo (coord.), El Acuerdo de Asociación Transpacífico (TPP)¿Bisagra o confrontación entre el Atlántico y el Pacífico?, México, UNAM, Instituto de Investigaciones Jurídicas, 2013, pp. 23-24.

9 El TTIP es un acuerdo de libre comercio megarregional actualmente en proceso de negociación entre los Estados Unidos y los Estados miembros de la UE. ElTTIP fue concebido inicialmente en noviembre de 2011, al final de la celebración del Sexto Encuentro del Consejo Económico Transatlántico (es decir, teniendo como contexto al transcurrir de los efectos de la crisis económica mundial, en especial la crisis de deuda europea que tuvo sus mayores efectos entre 2010-2012). Los líderes del diálogo transatlántico convocaron al Grupo de Trabajo de Alto Nivel para el Crecimiento y el Empleo que "identificara las medidas que incrementaran los intercambios entre los Estados Unidos y la UE en materia de comercio e inversión".

El Grupo de Trabajo concluyó que era recomendable la negociación de un tratado bilateral integral en comercio e inversiones. Posteriormente, en febrero de 2013, durante su Discurso sobre el Estado de la Unión, el presidente Barack Obama anunció el inicio de la primera ronda de negociación para la elaboración de un tratado de libre comercio transatlántico. La primera ronda de negociaciones inició en julio de 2013 y concluyó en octubre de 2015.

Leal-Arcas, Rafael, "Mega-regionals and Sustainable Development. The Transatlantic Trade and Investment Partnership and the Trans-Pacific Partnership”, Renewable Energy Law and Policy Review, vol. 4, 2015, p. 250. 
sector público, la protección de los derechos de propiedad intelectual y las inversiones. ${ }^{10}$

3) En el espacio euroasiático, los flujos del comercio se relacionan con un proyecto de integración megarregional basado en una organización internacional y con un proyecto de inversión en infraestructuras (este último, con la finalidad de agilizar los flujos comerciales). La organización de integración megarregional euroasiática es la Unión Económica Euroasiática (UEEA), creada en 2015, es una organización que agrupa a países ex soviéticos como Armenia, Bielorrusia, la Federación Rusa, Kazajistán y Kirguistán. ${ }^{11}$ Por su parte, el proyecto de inversión en infraestructuras euroasiático es la iniciativa Cinturón y Ruta, impulsada por China a partir de 2013.

2. Las potencias mundiales y los acuerdos megarregionales de libre comercio

En la actualidad, los Estados Unidos son una de las principales potencias interesadas en el desarrollo de acuerdos megarregionales de libre comercio. De acuerdo con Daniel S. Hamilton, el interés de Estados Unidos por impulsar la agenda de los acuerdos megarregionales (a través del TPP y el TTIP) puede obedecer a las siguientes razones:

1) Los dos acuerdos megarregionales reflejan el interés estadounidense por instrumentar una agenda de "liberalización competitiva" incluyendo a la mayor cantidad de países (siempre que acepten sus normas de liberalización) lo que conduce a la expansión global del comercio mundial. ${ }^{12}$

2) La negociación de los acuerdos megarregionales refleja la frustración de Washington y sus socios con el estancamiento de la Ronda de Doha y las negociaciones comerciales multilaterales. En los procesos de ne-

10 Cremona, Marise, "Negotiating the Transatlantic Trade and Investment Partnership (TTIP)”, Common Market Law Review, vol. 52, núm. 2, 2015, pp. 351-352.

11 Sobre la trayectoria del proceso de integración euroasiático alrededor de la UEEA veáse: Rocha Pino, Manuel, "La construcción de la Unión Euroasiática y la política exterior de Rusia”, Humania del Sur, Mérida, Universidad de los Andes, núm. 14, 2013.

12 Hamilton, Daniel S., “America's Mega-Regional Trade Diplomacy: Comparing TPP and TTIP”, The International Spectator, vol. 49, núm. 1, 2014, p. 84. 
gociación delTPP y delTTIP se incluye un conjunto limitado de países participantes (en teoría) comprometidos con el desarrollo de las negociaciones y la conclusión de los acuerdos. ${ }^{13}$

3) Tanto el TPP, así como las negociaciones del TTIP, se extienden mucho más allá de los acuerdos de libre comercio tradicionales. Además del componente de libre comercio, también se incluyen negociaciones sobre la estandarización de los productos, las normas y la coherencia regulatoria. ${ }^{14}$ ElTPP y el TTIP ofrecen a Estados Unidos la oportunidad de influir en la formulación de estándares así como el establecimiento de normas entre economías muy diversas ubicadas en la región de Asia-Pacífico, y la comunidad transatlántica, al mismo tiempo que aspira a presentar a las normas compartidas entre Estados Unidos y la UE como un núcleo referencial para los estándares mundiales. ${ }^{15}$ Como reconoce Eyal Benvenisti, sobre el TPP y el TTIP: "Los dos esfuerzos regionales para establecer estándares globales tienen un impacto indirecto significativo en aquellos países que no forman parte de ellos". ${ }^{16}$

El surgimiento de los acuerdos megarregionales puede contextualizarse en la proliferación de acuerdos preferenciales negociados entre miembros de la OMC con la finalidad de armonizar sus barreras no arancelarias; un ejemplo es la negociación del TTIP, el cual “...da una importancia igual o mayor a las barreras no arancelarias que a las barreras arancelarias". ${ }^{17}$ Como menciona Stephan Sberro, el desgaste de la centralidad de la OMC ha sido objeto de consideraciones teóricas sobre el cambio de la naturaleza del comercio internacional, con una menor importancia de las negociaciones arancelarias, en comparación con las no arancelarias y, sobre todo, debido a los nuevos flujos de producción y comercio que se basan en las cadenas de abastecimiento (supply chain trade).$^{18}$ Los países desarrollados "tratan de

13 Idem.

14 Ibidem. p. 85

15 Ibidem.

16 Benvenisti, Eyal, op. cit. p. 13.

17 Sberro, Stephan, "La negociación del TTIP: del interregionalismo a la gobernanza global”, Revista CIDOB d’Afers Internacionals, núm. 110, 2015, p. 78.

18 Idem. Como menciona Maxime Larivé: "El TTIP busca promover la liberalización del comercio multilateral, establecer nuevas reglas y normas a nivel mundial, y responder al aumento de las economías emergentes de gran alcance como China y Brasil. ElTTIP se enmarca 
Esta revista forma parte del acervo de la Biblioteca Jurídica Virtual del Instituto de Investigaciones Jurídicas de la UNAM

exportar sus regímenes reglamentarios sobre los más diversos aspectos, si bien su interés se centra en la política de competencia, los derechos de propiedad intelectual y la inversión extranjera". ${ }^{19}$

Otra característica del proceso de articulación de un acuerdo megarregional es que sus principales impulsores son actores que pueden ser considerados como "grandes potencias" mientras que otros participantes, como potencias regionales o países subdesarrollados, por lo general resultan pasivos durante el proceso de negociación frente a sus contrapartes con mayor poder. Dicho proceso agudiza, como mencionan Bouzas y Zelicovich, las asimetrías ya existentes en el régimen multilateral de comercio debido a que no todos los países participantes tienen la misma capacidad de impulsar una agenda. Para los autores, el dato más relevante en la utilización del regionalismo por parte de las grandes potencias, en las últimas décadas, ha sido no sólo el número de acuerdos negociados sino "la utilización estratégica de los acuerdos". ${ }^{20}$

Lo anterior significa que en las nuevas condiciones del régimen multilateral, las potencias no tienen el objetivo único de influir en su contenido: al mismo tiempo, las potencias aspiran a la construcción de “...regímenes regulatorios alternativos que eventualmente se conviertan en referencia para el resto de la comunidad internacional, anulando de facto la relevancia del statu quo multilateral”. ${ }^{21}$ Como señalan los autores:

...el régimen multilateral siempre funcionó con base en una combinación de reglas y ejercicio del poder, el desplazamiento de la OMC como ámbito para la creación de nuevas reglas y la gobernanza del comercio internacional acentuaría las asimetrías en la capacidad de los Estados para crear y promover nuevas disciplinas. En un escenario de este tipo muchos países en desarrollo verían limitadas las opciones de actualización de sus marcos regulatorios quedando dependientes, en la práctica,

como el acuerdo que permite la creación de puestos de trabajo a ambos lados del Atlántico e impulsar el lento motor económico europeo”. Larivé, Maxime H. A., “TTIP: A Mega-Free Trade Agreement Lost in Translation”, en Roy, Joaquin (ed.), A New Atlantic Community:The European Union, the US and Latin America, Miami, University of Miami, Miami-Florida European Union Center/Jean Monnet Chair, 2015, p. 82.

19 Zabalo, Patxi, op. cit., p. 2.

20 Bouzas y Zalikovich, op. cit., p. 977.

21 Idem. 
Esta revista forma parte del acervo de la Biblioteca Jurídica Virtual del Instituto de Investigaciones Jurídicas de la UNAM

de las modalidades que surjan del entramado de "intereses ofensivos" promovidos por los actores económicos más activos e influyentes en los países desarrollados. ${ }^{22}$

A continuación se describirán las consencuencias de la conformación de los acuerdos megarregionales de libre comercio para el sistema mundial de comercio y, especialmente, para los actores que han sido excluídos de los mismos.

\section{Los acuerdos megarregionales y la gobernanza del sistema mundial de comercio}

Un claro ejemplo en la competencia por establecer las nuevas normatividades y los estándares del sistema mundial de comercio (con especial referencia a China), mediante los nuevos acuerdos preferenciales, ahora megarregionales, lo evidenció el presidente Barack Obama durante su discurso realizado el 5 de octubre de 2015. En dicho discurso, Obama saludaba la conclusión de las negociaciones del TPP llevadas a cabo en Atlanta por los representantes de los países que integran el acuerdo. El presidente estadounidense enfatizó:

...no podemos permitir que países como China escriban las reglas de la economía global. Debemos escribir esas reglas, la apertura de nuevos mercados a los productos estadounidenses, mientras que establecemos altos estándares para la protección de los trabajadores y la preservación de nuestro medio ambiente... El acuerdo fortalece nuestras relaciones estratégicas con nuestros socios y aliados en una región que será vital para el siglo XXI. Es un acuerdo que pone a los trabajadores americanos primero y ayudará a las familias de clase media salir adelante. ${ }^{23}$

Posteriormente, en febrero de 2016, en su discurso pronunciado durante la ceremonia de la firma del TPP, el presidente Obama hizo una nueva referencia a la importancia del acuerdo en la definición de las normas del sistema mundial de comercio y la relación de dicho proceso con China: "El

22 Idem.

23 Obama, Barack, Statement by the President on the Trans-Pacific Partnership, Washington, The White House Office of the Press Secretary, 5 de octubre de 2015, disponible en: https: / /www. whitehouse.gov/the-press-office/2015/10/05/statement-president-trans-pacific-partnership (fecha de consulta: 8 de junio de 2016). 
Esta revista forma parte del acervo de la Biblioteca Jurídica Virtual del Instituto de Investigaciones Jurídicas de la UNAM

TPP permite a Estados Unidos — y no a países como China - escribir las reglas del siglo XXI, lo cual es especialmente importante en una región tan dinámica como la de Asia-Pacífico". ${ }^{24}$

En este sentido, puede considerarse que los proyectos de integración megarregional son la apuesta de algunas potencias (como los Estados Unidos, la UE, Rusia o China) en la articulación del sistema multilateral de comercio perteneciente al mundo posterior al periodo de crisis económica. La competencia por instituir las reglas económicas y comerciales puede identificarse como una prioridad de las potencias que impulsan los proyectos de integración: "Se piensa que los acuerdos megarregionales son motivados no solo por objetivos simplemente económicos sino, más importante aún, por consideraciones geopolíticas (o simplemente por objetivos políticos internacionales)...” ${ }^{25}$ Desde la perspectiva de Tamás Novák, la emergencia de China como potencia mundial ha sido una de las causas de la traslación de consideraciones geopolíticas a una cuestión, como los procesos de integración regional, que anteriormente habrían tenido como prioridad a las consideraciones geoeconómicas (como la eliminación de las barreras no arancelarias): “...el poder blando de algunos países emergentes, y especialmente de China, puede retar al poder blando de Estados Unidos y la Unión Europea”. ${ }^{26}$

Por otra parte, la articulación de los acuerdos de integración megarregional igualmente puede modificar a la estructura del sistema internacional (más allá de las cuestiones comerciales). Como lo define Sarah Beringer, en el caso del TTIP, el acuerdo megarregional: "Coloca nuevas reglas para la regulación económica global”. ${ }^{27}$ Dichas reglas deberían ser asumidas por el

24 Obama, Barack, Statement by the President on the Signing of the Trans-Pacific Partnership, Washington, The White House, Office of the Press Secretary, 3 de febrero de 2016, disponible en: https: / /www. whitehouse.gov/the-press-office/2016/02/03/statement-president-signingtrans-pacific-partnership (fecha de consulta: 8 de junio de 2016).

25 Novák, Tamás, “Global Political and Economic Restructuring through Free Trade Agreements (FTAs)”, en Roy, Joaquin (ed.), A New Atlantic Community: The European Union, the US and Latin America, Miami, University of Miami, Miami-Florida European Union Center/Jean Monnet Chair, 2015, p. 31.

26 Ibidem, pp. 31 y 32.

27 Beringer, Sarah, "The TTIP from a German Perspective: Economic Interests and Political Discourse”, en Roy, Joaquin (ed.), A New Atlantic Community: The European Union, the US and Latin America, Miami, University of Miami, Miami-Florida European Union Center/Jean Monnet Chair, 2015p. 66. 
resto de los actores internacionales en un proceso de armonización regulatoria: quienes rechacen las nuevas regulaciones podrían quedar marginados de la nueva gobernanza global.

El surgimiento de los proyectos de integración megarregional representa un fenómeno de cambio en el sistema internacional impulsado por las grandes potencias. Ya sea que se realicen los proyectos o fracasen por motivos políticos internos de algunos actores (como el movimiento de oposición social alTTIP en algunos países de la UE), la aparición de los proyectos tendrá consecuencias para el sistema multilateral de comercio. ${ }^{28}$

A continuación, se describirá una alternativa a los proyectos de integración megarregional como el TPP y el TTIP en el caso de la iniciativa Cinturón y Ruta impulsada por China. El proyecto CYR puede considerarse una política instrumentada por China para evitar su exclusión en la generación de las normas del nuevo sistema mundial de comercio.

\section{LA POLIITICA EXTERIOR DE CHINA DURANTE EL GOBIERNO DE Xi JiNPING: LA INICIATIVA CiNTURÓN Y RUTA}

Para comprender los objetivos que buscan alcanzar los proyectos del gobierno de Xi Jinping (iniciado en 2012), orientados a la estructuración de un conjunto de mecanismos de integración megarregional, resulta necesario realizar una descripción de la actual política exterior de China, que durante el gobierno del presidente Xi se ha caracterizado por la continuación de algunos de los principios del anterior gobierno, encabezado por Hu Jintao (2002-2012), al mismo tiempo que ha incorporado nuevas prioridades.

David Swaine identifica algunos elementos diplomáticos que pueden considerarse una continuación del gobierno anterior, en especial la necesidad de seguir manteniendo un entorno internacional estable y amistoso para los proyectos de desarrollo de China. Esta correlación entre los planes de desarrollo interno y la estabilidad del sistema internacional resulta co-

28 Deutsche Welle, “TTIP: la UE y EE.UU. seguirán negociando”, DW.com, 15 de septiembre de 2016, disponible en: http://www.dw.com/es/ttip-la-ue-y-ee-uu-seguir\%C3\%Aln-ne gociando/a-19554915 (fecha de consulta: el 15 de septiembre de 2016). 
Esta revista forma parte del acervo de la Biblioteca Jurídica Virtual del Instituto de Investigaciones Jurídicas de la UNAM

herente con los principios generales de la doctrina del desarrollo pacífico instrumentada por el gobierno de Hu Jintao. ${ }^{29}$

En principio, la doctrina del desarrollo pacífico se ha mantenido como parte del discurso oficial del gobierno chino, así se demostró en la intervención del presidente Xi durante la cumbre anual de la Asamblea General de la Organización de las Naciones Unidas (ONU) en septiembre de 2015. ${ }^{30}$ En su discurso, el presidente Xi mencionó: "Estamos comprometidos con un desarrollo pacífico. No importa cómo evolucione el panorama internacional o lo fuerte que llegue a ser China, China nunca buscará ninguna hegemonía, expansión o esfera de influencia”. ${ }^{31}$

Al mismo tiempo, si bien China mantiene un discurso sobre la necesidad de mantener relaciones pacíficas y estables en el sistema internacional, dicho contexto tiene una limitación básica; es decir, el mantenimiento de los principios doctrinales de la política exterior de China como el respeto a su soberanía y la estricta defensa de su integridad territorial (aspectos que involucran a conflictos territoriales que China mantiene con algunos países ubicados en el Sureste de Asia por las islas Spratly, en el Mar del Sur de China; en el caso del conflicto por la islas Diaoyu-Senkaku con Japón, y debido la cuestión de Taiwán). Sin embargo, los principios de protección y defensa de la integridad territorial no han sido un impedimento para que China mantenga la prioridad de establecer relaciones económicas y comerciales basadas en un pragmatismo diplomático, como en el caso de las relaciones entre China y Taiwán (especialmente durante el periodo de gobierno de Ma Yingjiu en Taiwan (2008-2016)). ${ }^{32}$

Asimismo, Swaine indentifica otros aspectos que pueden considerarse aportaciones propias de la política exterior del gobierno de Xi Jinping:

29 Swaine, David R., "Xi Jinping on Chinese Foreign Relations: The Governance of China and Chinese Commentary”, China Leadership Monitor, núm. 48, 2015, p. 2.

30 Sobre la doctrina del desarrollo pacífico, véase Rocha Pino, Manuel de Jesús, "China en transformación: la doctrina del desarrollo pacífico”, Foro Internacional, núm. 186, 2006, pp. 706-719.

31 Xi Jinping, "China, el actor silencioso", El País, 3 de octubre, disponible en: http: / /in ternacional.elpais.com/internacional/2015/10/03/actualidad/1443887772_770834.html (fecha de consulta: el 5 de junio de 2016).

32 Connelly, Marisela, Historia de Taiwan, México, El Colegio de México, 2014, pp. 341 512 . 
1) Una simultaneidad entre las aspiraciones de desarrollo y estabilidad con una afirmación de la defensa de los intereses fundamentales de China centrados en los mencionados principios doctrinales de la política exterior de Beijing. ${ }^{33}$

2) Un fuerte énfasis en el papel de liderazgo que debe desarrollar la ONU en áreas específicas, incluyendo la ciber-seguridad y la lucha contra el terrorismo. ${ }^{34}$ En este aspecto debe resaltarse la significación simbólica (el poder blando) del discurso del presidente Xi en la Asamblea General de la ONU de 2015.

$\mathrm{Al}$ otorgar mayores atribuciones a la ONU, el gobierno chino aspira a que ciertos temas, que pueden generar conflictividad entre las grandes potencias, sean negociados en el ámbito de los mecanismos multilaterales y así evitar escenarios de riesgo (como en el caso de la relación China-Estados Unidos) en un contexto internacional inestable. Los conflictos que se desarrollan actualmente en Medio Oriente (con el involucramiento creciente de potencias en Siria), o el enfrentamiento entre Rusia y Occidente por la cuestión de Crimea, han llevado a China a estructurar una política que evite dichos escenarios de riesgos. La actual elección multilateral de China tiene una finalidad pragmática en beneficio de un orden internacional estable.

3) La creación de nuevas instituciones económicas y financieras internacionales (específicamente asiáticas) como el Banco Asiático para Inversiones en Infraestructura (BAII) y el Fondo de la Ruta de la Seda (FRS)..$^{35}$ De acuerdo con Ajay Chhibber, existen cuatro razones que han llevado a un actor como China a impulsar la creación de nuevas instituciones financieras como el BAII: 1) las necesidades de financiación para la nueva infraestructura en Asia (debido a la capacidad limitada de las instituciones tradicionales como el Fondo Monetario Internacional o el Banco Asiático de Desarrollo); 2) la necesidad de nuevas políticas de desarrollo sostenible; 3) los crecientes intercambios Sur-Sur para cooperar en actividades productivas (ya no sólo para los programas de desarrollo o asistencialistas); 4) la lenta reforma de la arquitectura financiera global. ${ }^{36}$

33 Swaine, David, op. cit. p. 3.

34 Idem.

35 Idem.

36 Chhibber, Ajay, “China's One Belt One Road Strategy: The New Financial Institutions 
Esta revista forma parte del acervo de la Biblioteca Jurídica Virtual del Instituto de Investigaciones Jurídicas de la UNAM

4) La instrumentación de una nueva estrategia, a gran escala, de desarrollo económico megarregional y transcontinental como en el caso de la Iniciativa Cinturón y Ruta. Los proyectos de conectividad del CYR enlazan, mediante la construcción de infraestructura, a la costa oriental y las provincias occidentales de China (como Xinjiang y Tíbet) con Asia central y Europa (en la vertiente del CERS) y a China oriental y meridional con el Sureste de Asia, la cuenca del Océano Índico, África y el sur del Mediterráneo (en la vertiente de la RSM-XXI). ${ }^{37}$

5) La refinición de las relaciones de cooperación entre las grandes potencias a través de un nuevo concepto: "el Nuevo Modelo de Relaciones entre Grandes Potencias". ${ }^{38}$

6) Un rechazo a la idea de que cualquier nación (incluyendo China) puede servir como un modelo de desarrollo para otras naciones. ${ }^{39}$

La directiva anterior se corresponde con los Cinco Principios de Coexistencia Pacífica de China adaptados al contexto actual. ${ }^{40}$ El proyecto CYR

and India's Options", Working Paper núm. 2015-155, Nueva Delhi, National Institute of Public Finance and Policy, 2015, pp. 8-11.

Algo relevante en la creación de las nuevas instituciones como el BAII es que sus normas no tienen como prioridad el referente de la ayuda condicionada, como ocurre con otras instituciones como el Banco Mundial o los fondos de ayuda para el desarrollo de la UE: algo que puede significar la emergencia de "un nuevo paradigma” en los mecanismos de cooperación Sur-Sur “más allá de la solidaridad emocional del anticolonialismo”. Idem.

Sin embargo, un aspecto negativo derivado de la falta de condicionalidad de los fondos de financiamiento puede consistir en que algunos países no elegibles para recibir fondos de ayuda, debido al carácter autoritario de sus sistemas políticos, o el déficit en la situación de los derechos humanos de sus poblaciones, tendrían acceso a fondos de financiamiento que, anteriormente, no habrían podido obtener. Dicho factor alteraría la promoción de los valores y la buena gobernanza a nivel mundial.

37 Swaine, David, op. cit., p. 3.

38 Idem.

39 Idem.

40 Los Cinco Principios de Coexistencia Pacífica se acordaron en junio de 1954, durante una reunión entre el ministro de relaciones exteriores chino, Zhou Enlai, y el primer ministro de la India, Jawaharlal Nehru, para sustentar la relación bilateral que mantenían los dos países en ese momento; hasta ahora siguen siendo un elemento fundamental de la política exterior china. Los principios son: 1) respeto mutuo por la integridad territorial y la soberanía entre los países; 2) no agresión; 3) no interferencia en los asuntos internos de otras naciones; 4) igualdad y beneficio mutuo, y 5) coexistencia pacífica. 
Esta revista forma parte del acervo de la Biblioteca Jurídica Virtual del Instituto de Investigaciones Jurídicas de la UNAM

señala que, por necesidad, el gobierno chino deberá mantener negociaciones con una diversidad amplia de regiones, países y regímenes políticos. Las características de informalidad y flexibilidad de dicho proyecto, como se verá a continuación, conllevan de manera inherente que el gobierno chino no se encuentra interesado en transmitir o propagar sus propias preferencias políticas o sus planes de desarrollo a otros actores. Dicha cuestión, desde la perspectiva del gobierno del presidente Xi, debe quedar clarificada desde el inicio de una negociación con otro actor.

Además, como menciona Jing Men, durante el proceso de instrumentación de los proyectos del CYR, China debe tomar en cuenta las condiciones y características "geográficas, políticas, de seguridad, económicas, sociales y culturales" de cada uno de los países involucrados. ${ }^{41}$ En adición a los aspectos mencionados, la diversidad de los países asociados al CYR también genera una realidad que debe enfrentar el gobierno chino de "leyes complejas y variadas, normas y reglamentos que configuran el entorno de negocios en cada país" y aspectos como la lucha contra la corrupción, las normativas para la protección del medio ambiente y el enfrentamiento a amenzas como el terrorismo. ${ }^{42}$

\section{LA TRAYECTORIA DEL PROYECTO CINTURÓN Y RUTA (2013-2016)}

Los instrumentos de integración megarregional propuestos por el gobierno de Xi Jinping, hasta el momento, son: la Asociación Económica Integral Regional (RCEP, por sus siglas en inglés), propuesta en noviembre de 2012; el Área de Libre Comercio de Asia Pacífico (ALCAP), basada en un proyecto previo de la APEC, propuesta en noviembre de $2014 ;^{43}$ la Iniciativa Cintu-

${ }^{41}$ Men, Jing, “China's New Silk Road and EU-China Relations”, EU-China Observer, núm 1.15, Bruselas, College of Europe, 2015, p. 12.

42 Mingkang, Liu y Wenzhi, Lu, "Belt and Road Initiative needs Good Laws", China Daily, 22 de enero de 2016, disponible en: http: / /www.chinadaily.com.cn/opinion/2016-01 / 22 / content_23195259.htm (fecha de consulta: 10 de septiembre de 2016).

43 En lo que respecta al ALCAP, durante la cumbre del Foro de Cooperación Económica Asia-Pacífico (APEC) realizada en 2014, China propuso la creación de dicha Área de Libre Comercio. Esta iniciativa tiene como base a un proyecto de integración generado, previamente en el año 2004, en el contexto de APEC. La iniciativa del ALCAP puede considerarse un 
Esta revista forma parte del acervo de la Biblioteca Jurídica Virtual del Instituto de Investigaciones Jurídicas de la UNAM www.juridicas.unam.mx

rón y Ruta cuyos primeros lineamientos fueron propuestos oficialmente en septiembre de 2013. Además de los instrumentos anteriores, los proyectos de construcción de infraestructura del CYR contarán con dos instituciones financieras: el BAII, creado en 2015 y el FRS, creado en 2014. ${ }^{44}$

De acuerdo con Swaine, tanto especialistas chinos como extranjeros han reconocido que el CYR representa el proyecto de política exterior más amplio y trascedente instrumentado por el gobierno de Xi Jinping: el CYR es descrito por observadores chinos "como una «estrategia» muy importante y no sólo como una iniciativa económica. De acuerdo con algunos observadores externos, "se espera que el concepto tenga un lugar destacado en el Décimo Tercer Plan Quinquenal de China, que abarcará desde 2016 hasta 2020, y guíe a la estrategia nacional de inversiones durante ese período" ${ }^{45}$ Sin embargo, aunque el gobierno chino reconoce que el CYR es uno de los “conceptos claves” de su Décimo Tercer Plan Quinquenal, resulta claro que

proyecto de integración megarregional y transcontinental. Como menciona Juan José Ramírez Bonilla, el proyecto del ALCAP tiene su origen en una iniciativa del APEC Business Advisory Council (ABAC) formulada en 2004 (aunque no fue instrumentalizada en ese momento): “... durante 2004 y 2005, ABAC y un grupo de trabajo del Pacific Economic Cooperation Council (PECC) prepararon un estudio de factibilidad sobre el ALCAP y éste fue sometido por los representantes de ABAC a los "líderes de APEC", sin que hubiera tenido consecuencia alguna".

Ramírez Bonilla, Juan José, "APEC y el proyecto de la Free Trade Area of the Asia-Pacific. Entre el regionalismo abierto y el comercio regulado”, México y la Cuenca del Pacífico, núm, 10, 2015, p. 18.

44 En marzo de 2015, el gobierno chino anunció la convocatoria para los países interesados en incorporarse como miembros fundadores del BAII: los países que comunicaron dicho interés, en primera instancia, fueron principalmente asiáticos y europeos (incluyendo, de manera relevante, el anuncio de la incorporación primero del gobierno de Reino Unido en el mismo mes de marzo, seguido por Francia y Alemania).

El capital inicial del BAII fue de \$100 mil millones de dólares. Por su parte, el FRS contó con un capital inicial de $\$ 40$ mil millones de dólares "fondos dedicados exclusivamente al desarrollo de las redes comerciales y de transporte en los países y regiones a lo largo de la Nueva Ruta de la Seda”. A estos fondos se agregan \$25 mil millones de dólares destinados a los proyectos de la RSM-XXI e inversiones realizadas en los países de Asia central hasta el año 2013 por \$50 mil millones de dólares. Además, existe la participación de bancos de capital chino en los proyectos del CYR (como el China Investment Corporation, el China Development Bank Capital Company y el Export-Import Bank of China).

Sárvári, Balázs y Szeidovitz, Anna, "The Political Economics of the New Silk Road”, Baltic Journal of European Studies, vol. 6, núm. 1, 2016, p. 7.

45 Swaine, David R., "Chinese Views and Commentary on the "One Belt, One Road” Initiative”, China Leadership Monitor, núm. 47, 2015, p. 1. 
Esta revista forma parte del acervo de la Biblioteca Jurídica Virtual del Instituto de Investigaciones Jurídicas de la UNAM

el desarrollo exitoso de los proyectos del CYR requerirá del apoyo financiero, institucional y político tanto de China como de los países asociados a los proyectos. ${ }^{46}$

El origen de la iniciativa Cinturón y Ruta puede identificarse con la presentación de un proyecto de cooperación regional entre China y los países de Asia central formulado por el gobierno chino en 2013. Dicho proyecto, que fue denominado como el Cinturón Económico de la Ruta de la Seda, fue presentado por el presidente Xi ante el gobierno de Kazajistán durante una visita oficial a ese país en septiembre de 2013, en la ciudad de Astana. Durante su discurso, el presidente Xi enunció los objetivos del CERS: 1) fortalecer las políticas de comunicación; 2) mejorar la conectividad en comunicaciones y transportes “...para abrir los canales de comunicación del Pacífico al Mar Báltico”; 3) promover la facilitación del comercio; 4) mejorar la circulación monetaria; 5) fortalecer los contactos pueblo a pueblo. ${ }^{47}$

Posteriormente, en octubre de 2013, el presidente Xi presentó un proyecto de cooperación regional similar ante el Parlamento de Indonesia durante su visita a ese país: dicho proyecto fue denominado como la Ruta de la Seda Marítima del Siglo XXI. ${ }^{48}$ A su vez, durante el periodo 2014-2015, el gobierno chino elaboró una síntesis de ambos proyectos con la finalidad de agruparlos en un solo concepto político. Durante un tiempo, el nuevo concepto fue denominado como "Un Cinturón, una Ruta", aunque en 2015 fue reformulado como el CYR (la denominación oficial en la actualidad). Igualmente, durante 2015 la dirigencia del Partido Comunista Chino oficializó a los principios básicos del CYR.

En marzo de 2015, la Comisión Nacional para el Desarrollo y la Reforma (la instancia gubernamental responsable de supervisar la instrumentación del CYR), el Ministerio de Asuntos Exteriores y el Ministerio de Comercio

46 Diario del Pueblo, "6 conceptos claves que describen el 13 Plan Quinquenal de China”, Diario del Pueblo, 30 de octubre de 2015, disponible en: http://spanish.peopledaily.com. $\mathrm{cn} / \mathrm{n} / 2015 / 1030 / c 31619-8969356 . h t m l$ (fecha de consultado: 10 de septiembre de 2016).

47 Jinping, Xi, President Xi Jinping delivers Important Speech and Proposes to build a Silk Road Economic Belt with Central Asian Countries, Ministerio de Asuntos Exteriores de la República Popular China, Astana, 7 de septiembre, disponible en: http://www.fmprc.gov.cn/mfa_eng/to pics_665678/xjpfwzys iesgjtfhshzzfh_665686/t1076334.shtml (fecha de consulta: 22 de mayo de 2016).

48 Jinping, Xi, Speech by Chinese President Xi Jinping to Indonesian Parliament, ASEAN-China Centre, 3 de octubre de 2013, disponible en: http: / / www.asean-china-center.org/english/201310/03/c_133062675.htm (fecha de consulta: 22 de mayo de 2016). 
Esta revista forma parte del acervo de la Biblioteca Jurídica Virtual del Instituto de Investigaciones Jurídicas de la UNAM

de China publicaron el documento Visión y Acciones sobre el Cinturón Económico de la Ruta de la Seda y la Ruta de la Seda Marítima del Siglo XXI, en donde se especifican las cinco áreas de cooperación prioritarias del CYR: "Coordinación de políticas, facilidades para la conectividad, fluidez en el comercio, integración financiera y fondos para mantener los intercambios pueblo a pueblo". ${ }^{49} \mathrm{Al}$ mismo tiempo, en el documento se enfatizó el compromiso del gobierno chino con el mantenimiento de las estructuras del sistema mundial de comercio:

La iniciativa para la construcción del proyecto Cinturón y Ruta se agrega a la tendencia hacia un mundo multipolar, la globalización económica, la diversidad cultural y la tecnología avanzada; está diseñada para mantener el régimen de libre comercio mundial y la economía mundial abierta en el espíritu de la cooperación regional abierta. Se encuentra dirigida a la promoción del flujo ordenado y libre de los factores económicos, la asignación altamente eficiente de los recursos y la profundización en la integración de los mercados; la iniciativa estimula a los países a lo largo del Cinturón y Ruta para lograr una mayor coordinación de la política económica y la ampliación de la cooperación regional con normas más estrictas.. ${ }^{50}$

Como parte de las políticas de desarrollo interno, el CYR tiene como prioridad la atracción de inversiones a las provincias menos desarrolladas de China, como Xinjiang y Tíbet, ubicadas en la región occidental del país, y con ello incrementar la conectividad entre la costa oriental con sus regiones de frontera con Asia central. ${ }^{51}$ De acuerdo con el documento Visión y Acciones sobre el Cinturón Económico de la Ruta de la Seda y la Ruta de la Seda Marítima del Siglo XXI, son 18 los gobiernos provinciales de China que participa-

49 Shin Jong-ho, "Implications of China's Yidai Yilu Strategy on the Korean Peninsula", Online Series CO 15-20, KINU, Seúl, 2015, p. 3, disponible en: http://www.kinu.or.kr/2015/ eng/0812/co15-20.pdf (fecha de consulta: 2 de junio de 2016).

Véase: Comisión Nacional para el Desarrollo y la Reforma, Ministerio de Asuntos Exteriores y Ministerio de Comercio de China, Vision and Actions on Jointly Building Silk Road Economic Belt and 21st-Century Maritime Silk Road, Comisión Nacional para el Desarrollo y la Reforma, Beijing, 28 de marzo de 2015, disponible en: http://en.ndrc.gov.cn/newsrelease/201503/ t20150330_669367.html (fecha de consulta: 2 de junio de 2016).

50 Idem.

51 Jisi, Wang, “«Marching Westwards»: The Rebalancing of China's Geostrategy", en Binhong, Shao (ed.), TheWorld in 2020 According to China: Chinese Foreign Policy Elites discuss Emerging Trends in International Politics, Leiden, Brill, 2014, p. 131. 
Esta revista forma parte del acervo de la Biblioteca Jurídica Virtual del Instituto de Investigaciones Jurídicas de la UNAM

rán en los proyectos del CYR. Estas provincias chinas son: 1) manteniendo una conexión con Asia Central, las provincias ubicadas en el occidente y el noroeste como Xinjiang, Shaanxi, Gansu, Ningxia, Qinghai, y la Región Autónoma de Mongolia Interior; 2) Tíbet, Guangxi y Yunán mantendrán una conexión con el Sur de Asia y el Sudeste de Asia; 3) en la conectividad de transporte marítimo, la zona costera de la municipalidad de Shanghai y las provincias de Fujian, Guangdong, Zhejiang y Hainan se orientarán hacia el Sureste de Asia; 4) a través de los centros de transporte interiores de Chongqing se enlazarán los flujos comerciales de este a oeste, y 5) las tres provincias del noreste (Heilongjiang, Jilin y Liaoning) se conectarán con los proyectos con Rusia. ${ }^{52}$

Como parte de la política exterior de China, la instrumentación del CYR se contextualiza en las limitantes que comienza a evidenciar del modelo de establecimiento de asociaciones estratégicas con otros actores. Esto se debe a que China ya ha establecido vínculos de asociación estratégica con un número amplio de miembros del sistema internacional: con la mayoría de las grandes potencias, potencias emergentes, potencias medias y con algunas organizaciones internacionales de integración regional (como la UE o la Asociación de Naciones del Sureste de Asia [ANSEA]); desde la perspectiva de Beijing, resulta necesario incrementar y fortalecer el alcance de las políticas de cooperación económica en el esquema de las asociaciones..$^{53}$ En este sentido, las asociaciones estratégicas se presentan como los instrumentos diplomáticos (o plataformas institucionales) que pueden contribuir a incrementar las relaciones de interdependencia económica entre China y sus socios por medio de los proyectos del CYR. El objetivo (de manera ideal) es llevar a cabo un proceso de cooperación regional. ${ }^{54}$

52 Comisión Nacional para el Desarrollo y la Reforma, Ministerio de Asuntos Exteriores y Ministerio de Comercio de China, op. cit.

53 Idem

54 Feng Zhang, "China as a Global Force”, Asia \& the Pacific Policy Studies, vol. 3, núm. 1, 2016, pp. 122-124.

Sin embargo, debe resaltarse la excepción de Estados Unidos al respecto: desde el año de 1998, en que China propuso al gobierno de Bill Clinton el establecimiento de un acuerdo de asociación estratégica, la primera potencia mundial ha sido renuente a oficializar un vínculo de asociación con China. Idem. p. 122.

En noviembre de 2009, durante una visita oficial a China, el presidente estadounidense Barack Obama propuso al gobierno de Hu Jintao la conformación de una relación estratégica denominada Grupo de los 2 (G-2) cuyos términos fueron rechazados por el gobierno chino. 
Esta revista forma parte del acervo de la Biblioteca Jurídica Virtual del Instituto de Investigaciones Jurídicas de la UNAM

\section{LAS CARACTERÍSTICAS Y OBJETIVOS BÁSICOS DEL CYR}

\section{Características básicas del CYR}

De acuerdo con las proyecciones del gobierno chino, el CYR abarca a 64 países, ubicados principalmente en Asia, África y Europa, los cuales se encontrarían interesados en participar en sus proyectos (lo que significa 4400 millones de personas o $63 \%$ de la población mundial). ${ }^{55}$ El conjunto de estos actores significa un producto global de $\$ 21$ billones de dólares (el doble del PIB anual de China o el 29\% del PIB mundial). Debido a su extensión, de acuerdo con Feng Zhang, el CYR representa un proyecto planeado por "la diplomacia económica de China dirigido a la mitad del mundo" y con la posibilidad de aumentar e incorporar a más socios, debido su carácter abierto y flexible. ${ }^{56}$

La finalidad de la instrumentación de los proyectos de inversión en infraestructura del CYR es aumentar la conectividad entre los participantes y, con ello, la interdependencia económica entre los principales países en el espacio euroasiático. Sin embargo, este objetivo básico tiene una dificultad representada por el déficit de infraestructura existente actualmente en Eurasia. Por su parte, el gobierno chino proyecta el déficit de infraestructura en Eurasia en $¥ 8$ billones de yuanes ( $\$ 3.2$ billones de dólares). La única forma de evitar las dificultades que representa dicho déficit es mediante la inversión con la finalidad de incrementar la conectividad y los flujos comerciales. ${ }^{57}$

En ese momento, el primer ministro Wen Jiabao declaró: “China sigue una política exterior independiente y no se alineará con ningún país o bloque de países... las cuestiones globales deben ser decididas por todos los países del mundo en lugar de que lo hagan uno o dos países". Jiabao, Wen, “Wen: China disagrees to so-called G2", Xinhua, 18 de noviembre de 2009, disponible en: http://china.org.cn/world/obamas_asia_tour/2009-11/18/content_18913266.htm (fecha de consulta: 8 de septiembre de 2016).

55 Hasta el momento (segundo semestre de 2016), el gobierno chino no ha presentado una agenda oficial para la instrumentación de los proyectos del CYR en América Latina. Estos proyectos podrían ser coordinados de manera bilateral o a través de un mecanismo de cooperación sino-latinoamericano como el Foro de Cooperación China-CELAC.

56 Feng Zhang, op. cit. p. 123.

57 Deng Yaqing, “A Shared Path”, Beijing Review, 10 de julio de 2014, p. 33. 
Esta revista forma parte del acervo de la Biblioteca Jurídica Virtual del Instituto de Investigaciones Jurídicas de la UNAM

Como menciona David Arase, la infraestructura impulsada por los proyectos del CYR puede ser "dura" o "blanda". Como infraestructura dura pueden mencionarse a sectores como los materiales de construcción (acero, cemento, vidrio, etcétera), el equipamiento de ferrocarriles, carreteras, puertos, oleoductos y gasoductos, parques industriales, instalaciones aduaneras, servicios de cómputo, etcétera. La infraestructura "blanda" se refiere a la estructura institucional y jurídica para la promoción del comercio y las inversiones (como la diplomacia, las instituciones financieras para el desarrollo, los acuerdos de cooperación económica, los foros de cooperación multilateral, la investigación académica, el intercambio cultural, el turismo, etcétera). ${ }^{58}$

Lo anterior significa que el aumento de la interdependencia económica entre China y sus socios puede repercutir, no solamente, en el desarrollo de amplios proyectos de construcción de infraestructura: de la misma manera, el desarrollo institucional tendrá un impacto en la promoción del comercio y la cooperación económica regional e internacional, así como en la construcción de nuevas normas para el sistema internacional. Como señala Jing Men: "Este será un proceso de aprendizaje para todos los países involucrados y, sin duda, para dichos países tomará tiempo aprender, aceptar y asimilar las nuevas reglas". ${ }^{59}$

Los planes de conectividad del CYR-CERS-RSM-XXI tienen las siguientes características básicas de operación:

1) El objetivo inicial del CYR ha sido reforzar las relaciones de cooperación e interdependencia entre China y sus vecinos (con especial referencia a Xinjing y Tíbet): por esta razón, la proyección global del CYR se encuentra subordinada a los proyectos que sean desarrollados en el espacio euroasiático.

2) La iniciativa, en su forma actual, no se encuentra definida. El concepto político CYR es "un concepto paraguas" en el que pueden converger una variedad de proyectos. El desarrollo de los proyectos se llevará a cabo en las estructuras diplomáticas que el gobierno chino ha constituido desde por lo menos 1993 (año en que se formalizó la asociación

58 Arase, David, “China's two Silk Roads Initiative: What it means for Southeast Asia”, en Singh, Daljit (ed.), Southeast Asian Affairs 2015, Singapur, ISEAS, 2015, p. 25.

59 Jing Men, op. cit. p. 13. 
estratégica China-Brasil), con especial referencia a las asociaciones estratégicas que China mantiene con una variedad de actores internacionales. ${ }^{60}$ Como señalan Francisco J. Haro y Rosángel Hernández, las asociaciones estratégicas de China son "una de las herramientas diplomáticas más empleadas por su gobierno". ${ }^{61}$ Hasta el momento, China ha establecido acuerdos de asociación, asociación estratégica o asociación estratégica integral con más de 65 países y organizaciones regionales y subregionales: "la instrumentación del CYR seguramente reforzará a los acuerdos existentes de asociación bilateral" ${ }^{62}$

Al carácter específico (flexible y ad hoc) de la agenda de cada asociación estratégica bilateral se podrá agregar la variabilidad de los proyectos del CYR “así como sus muchas rutas potenciales" respaldadas por dicho concepto. ${ }^{63}$ Además de las asociaciones estratégicas, existen otros instrumentos desarrollados por el gobierno chino que pueden tener la función de plataformas institucionales que sirvan para coordinar la instrumentación de los proyectos: estas pueden ser la Organización de Cooperación de Shanghai (OCS), el Foro de Cooperación China-África (FOCAC) y el Diálogo $16+1$ conformado por China y algunos países de Europa Oriental y Central (algo notable de este foro es que integra a países europeos pertenecientes a la UE y a países no pertenecientes a la misma como Serbia o Macedonia). ${ }^{64}$

3) El CYR no se relaciona únicamente con el comercio y la cooperación económica (aunque hasta el momento la prioridad parece ser la racionalidad de los negocios y la maximización de los beneficios). De acuerdo con Sárvári y Szeidovitz, el proyecto también puede incumbir a cuestiones sociales, culturales y de cooperación en materia de segu-

60 Sárvári, Balázs y Szeidovitz, Anna, op. cit., p. 8.

${ }^{61}$ Haro Navejas, Francisco Javier y Hernández Mendoza, Rosángel, "Viaje al oeste, la asociación sino-mexicana: una posibilidad funcionalista”, Foro Internacional, núm. 224, 2016, p. 419.

62 Lingliang, Zeng, "Conceptual Analysis of China's Belt and Road Initiative: A Road towards a Regional Community of Common Destiny”, Chinese Journal of International Law, agosto, 2016, p. 15.

63 Sárvári, Balázs y Szeidovitz, Anna, op. cit. p. 8.

64 Zuokui, Liu, The Role of Central and Eastern Europe in the Building of Silk Road Economic Belt, Beijing, China Institute of International Studies, 2014. Disponible en: http://www.ciis. org.cn/english/2014-09/18/content_7243192.htm (consultado el 12 de septiembre de 2016). 
ridad: la construcción de infraestructura puede crear las condiciones de conectividad "para el flujo de ideas, mercancías y bienes". ${ }^{65}$

En el caso del CERS, los proyectos de inversión tratarán de contrarrestar algunos problemas de seguridad en las regiones de frontera entre China y los países de Asia central como el terrorismo, el separatismo y el extremismo (especialmente en el caso de las actividades violentas de algunos grupos extremistas de la etnia uigur en Xinjiang). ${ }^{66}$ La agenda que asocia a la cooperación económica con la cooperación en materia de seguridad es uno de los pilares de la Organización de Cooperación de Shanghai. La OCS también tendrá la función de ser la plataforma institucional coordinadora de los proyectos de cooperación económica e inversiones del CERS en Eurasia central. ${ }^{67}$

\section{Objetivos básicos del CYR}

Como menciona Feng Zhang, el CYR es producto de factores políticos y económicos tanto internos como externos de China: "Es un caso típico de una decisión de política exterior influenciada tanto por los factores nacionales como internacionales". ${ }^{68}$ En el ámbito interno, los proyectos de China en el CYR parecen originarse en dos objetivos básicos: 1) la presión derivada por un exceso de capacidad productiva en ciertos sectores de la economía china y 2) el interés de China en avanzar en su proceso de modernización económica, en este caso mediante la consolidación de su estatus como potencia mundial. ${ }^{69}$ En el ámbito externo, el CYR es una respuesta a los proyectos de integración megarregional estadounidense como el TPP y el

65 Idem.

66 Ghouri, Ahmad, “Towards Greater Integration? Legal and Policy Directions of Chinese Investments in Pakistan on the Advent of the Silk Road Economic Belt", The Chinese Journal of Comparative Law, vol. 4, núm. 1, 2016, p. 39.

67 Sun Zhuangzhi, "Belt and Road will boost SCO Strength", China Daily, 22 de junio de 2016, disponible en: http://www.chinadaily.com.cn/opinion/2016-06/22/content_25798649. htm (fecha de consulta: 8 de julio de 2016).

68 Feng Zhang, op. cit. p. 125.

69 Fasslabend, Werner, "The Silk Road: A Political Marketing Concept for World Dominance", European View, vol. 14, núm. 2, 2015, p. 300. 
Esta revista forma parte del acervo de la Biblioteca Jurídica Virtual del Instituto de Investigaciones Jurídicas de la UNAM

TTIP (siendo elTPP uno de los objetivos de la política de pivote en Asia Pacífico instrumentada por el gobierno de Barack Obama a partir de 2011). ${ }^{70}$ Debe mencionarse que el CYR incluye a países que han sido excluidos del TTIP o elTPP como los pertenecientes a Asia central, el Sur de Asia, África y algunos países europeos que no pertenecen a la UE.

De acuerdo con Feng Zhang, el gobierno chino mantiene cinco objetivos económicos mediante la instrumentación del CYR:

1) La exportación de su exceso de capacidad productiva: "Mediante la promoción de los proyectos de infraestructura en los países pertenecientes a la red del CYR, China espera que estos le ayudarán a absorber parte de su exceso de capacidad". ${ }^{71}$ A su vez, el CYR forma parte del proceso de reforma económica en China que tiene como prioridad el fomento del consumo interno de la población en lugar de enfocarse a la inversión en actividades dedicadas a las exportaciones, tal como lo indican las prioridades formuladas por el Consejo de Estado de China en mayo de 2015. ${ }^{72}$

Algunos autores coinciden en que los funcionarios del Partido Comunista Chino (PCCh) encargados de planear los proyectos del CYR, en los niveles nacional y provincial, consideran que el desarrollo de la iniciativa es una manera de solucionar el problema del exceso de la capacidad productiva de China en sectores como los equipos industriales, acero, cemento, vidrio y los materiales de construcción en general. ${ }^{73}$ Como menciona Christopher K. Johnson: “...el CYR ofrece una oportunidad para ayudar a absorber el exceso de la capacidad productiva de China que su economía, crecientemente endeudada, simplemente no puede sostener". ${ }^{74}$

70 Ye, Min, "China and Competing Cooperation in Asia-Pacific: TPP, RCEP, and the New Silk Road”, Asian Security, vol. 11, núm. 3, 2015, pp. 216-218.

71 Zhang, Feng, op. cit. p. 125

72 Consejo de Estado de la República Popular China, "China sets Economic Reform Priorities for 2015”, Xinhua, 18 de mayo de 2015, disponible en: http: / / news.xinhuanet.com / english /2015-05/18/c_134249634.htm (fecha de consulta: 30 de mayo de 2016).

73 Chhibber, Ajay, op. cit. p. 7.

74 Johnson, Christopher K., President Xi Jinping's "Belt and Road"Initiative, Washington, CSIS Freeman Chair on China Studies, 2016, p. v, disponible en: http://csis.org/files/publication/160328_Johnson_PresidentXiJinping_Web.pdf(fecha de consulta: 11 de junio de 2016). 
Al mismo tiempo, el capital chino es favorable para el traslado de sectores industriales que usan una fuerza de trabajo intensiva a algunos países subdesarrollados en donde los salarios son menores en comparación a los de China. De esta manera, la reforma económica trata de mantener la competitividad debido al aumento de los costos de producción en China. ${ }^{75}$ Un ejemplo de ello es la proyección de inversiones productivas del capital chino en África. ${ }^{76}$

2) El gobierno chino pretende orientar parte de sus reservas en divisas de $\$ 3.7$ billones de dólares hacia la inversión en actividades productivas y las inversiones en infraestructura en el extranjero que sean consideradas "una buena opción". La diversificación de la inversión en dichos proyectos "promete un mayor beneficio en el largo plazo, al mismo tiempo que contribuye al crecimiento económico global". ${ }^{77}$

3) Los proyectos del CYR pueden asegurar a China la diversificación de sus proveedores de energía y así depender menos de los mercados de energéticos ubicados en Medio Oriente. Al incrementar las relaciones con sus vecinos ubicados en Asia central y Rusia, el gobierno chino aspira a superar su vulnerabilidad energética. ${ }^{78}$

4) Existe un claro nexo entre la instrumentación de los proyectos del CYR y la necesidad de estabilidad de China en sus provincias fronteri-

Igualmente, un editorial de la revista The Economist, publicado en febrero de 2016, señaló que las raíces del problema del exceso de la capacidad productiva se encuentran en la respuesta de China a la crisis financiera de 2008 (sin embargo, el exceso de la capacidad productiva es un problema que también afecta a las economías occidentales debido a la crisis bancaria estadounidense y la crisis de deuda europea): "Los funcionarios chinos transfirieron dinero indiscriminadamente a empresas estatales para la inversión en infraestructura y la industria pesada... La sobreproducción ha contribuido a la deflación: en el mes de enero de 2016 se tuvo el mes número 47 de descensos de precios de forma consecutiva. La caída de los precios de la producción se suma a la presión sobre las empresas estatales endeudadas". Véase "The March of the Zombies China's Excess Industrial Capacity Harms its Economy and Riles its Trading Partner", The Economist, 27 de febrero de 2016, disponible en: http: / / www.economist. $\mathrm{com} /$ news / business / 21693573 -chinas-excess-industrial-capacity-harms-its-economy-and-riles-itstrading-partners-march (fecha de consulta: 3 de julio de 2016).

75 Feng Zhang, op. cit. p. 124.

76 Davies, Martyn, Draper, Peter y Edinger, Hannah, "Changing China, Changing Africa: Future Contours of an Emerging Relationship”, Asian Economic Policy Review, vol. 9, núm. 2, 2014, p. 181.

77 Feng Zhang, op. cit., p. 124.

78 Idem. 
zas como Xinjiang o Tíbet. Al mismo tiempo, el desarrollo industrial de las regiones occidentales de China significaría la conformación de un polo de desarrollo complementario a las regiones industriales ubicadas en la costa oriental del país (vulnerables a ataques en caso de un conflicto militar). ${ }^{79}$

De manera significativa, como menciona Kishore Mahbubani, mientras que a partir de 2011 el gobierno Barack Obama instrumentó su política de pivote para Asia Pacífico, el gobierno de Xi Jinping ha concentrado parte de sus proyectos de inversión y desarrollo en incrementar sus relaciones de interdependencia con los actores ubicados en Eurasia central y Europa. ${ }^{80}$ Desde una perspectiva realista, de acuerdo con Feng Zhang, el CYR puede considerarse la respuesta de China para contener a la política estadounidense del pivote para Asia-Pacífico “con un mayor énfasis en la diplomacia regional". ${ }^{81}$ Sin embargo, de una manera ideal, desde la perspectiva de Wang Jisi el incremento de la interdependencia entre China y los páises euroasiáticos, mediante los proyectos del CYR, podría significar también una estabilización de las relaciones entre China y Estados Unidos (al generarse una prioridad compartida para mantener, igualmente, la estabilidad en el espacio euroasiático frente a amenazas como el extremismo y el terrorismo). ${ }^{82}$

79 Idem

80 Mahbubani, Kishore, comentario realizado en la mesa de diálogo Eurasia and the Modern Silk Road, realizada en el World Economic Forum, Davos, 2016, disponible en: https: //Www. weforum.org/events / world-economic-forum-annual-meeting-2016/sessions / eurasia-and-the-modernsilk-road/ (fecha de consulta: 26 de junio de 2016).

81 Feng Zhang, op. cit. p. 124. También, véase, ChenYu-Wen, "A Research Note on Central Asian Perspectives on the Rise of China. The Example of Kazakhstan”, Issues and Studies, Taipei, vol. 51, núm. 3, 2015, pp. 66 y 67.

82 De acuerdo con Wang Jisi, el aumento de la interdependencia entre China y sus vecinos centroasiáticos, impulsada por su "Nueva Ruta de la Seda", también puede interpretarse como una estrategia del gobierno chino para “establecer relaciones más balanceadas entre China y Estados Unidos”, con la finalidad de fortalecer la confianza entre ambos actores y evitar los escenarios de conflicto que ha podido generar la política estadounidense de pivote en Asia Pacífico: "El desplazamiento hacia el Este en el enfoque estratégico de la administración Obama, el cual ha sido interpretado como una manera de defenderse de las ambiciones de China, también se enfoca en Asia del Este... En adición, la competición sino-estadounidense en Asia del Este se está convirtiendo en una situación de «suma cero». Sin embargo, si China «marcha hacia el oeste», el potencial para la cooperación sino-estadounidense en áreas como 
5) Mediante el CYR el gobierno chino aspira a formar parte del grupo de actores internacionales que definirán la agenda de la gobernanza del comercio global, y en general de los asuntos económicos internacionales, en los próximos años:

[el CYR] Es la respuesta de China a la gobernanza económica mundial posterior a la crisis de 2008, y es una iniciativa clave para el desarrollo de su capacidad para la elaboración de normas orientadas a la regulación del comercio mundial y las finanzas. En lo particular, el proyecto promoverá la negociación de varios tipos de acuerdos de libre comercio, construirá nuevos centros internacionales de tipo económico, financiero, comercial y para la distribución de productos y por lo tanto asegurará una posición central para China, aunque no dominante, en la gestión económica internacional. ${ }^{83}$

De cumplirse las proyecciones anteriores, los planes de inversión del gobierno chino podrían producir "algunos beneficios locales y regionales y construirán una red de infraestructura para la conectividad transcontinental" originada en China y orientada hacia China. ${ }^{84}$

Sin embargo, debe resaltarse el rechazo, por parte del discurso oficial, a asumir una centralidad “dominante” por parte de China en los proyectos del CYR. Durante su discurso de inauguración de la Cumbre del G-20 efectuada en Hangzhou, en septiembre de 2016, el presidente Xi Jinping se refirió a la instrumentación del CYR en la siguiente forma:

...sus objetivos son complementar y mejorar los actuales mecanismos internacionales para lograr una cooperación de beneficio mutuo y desarrollo común. La iniciativa de China no es la actuación de un solo individuo. Al contrario, es una invitación abierta a todos. Es un proyecto no para establecer una esfera de influencia propia de China, sino para apoyar el desarrollo común de todos los países. No tiene el propósito de construir el jardín trasero propiedad de China, sino un jardín compartido por todos los países. ${ }^{85}$

las inversiones, la energía, la lucha contra el terrorismo, la no proliferación nuclear y el mantenimiento de la estabilidad regional se incrementará”. Wang Jisi, op. cit. pp. 133 y 134.

83 Zhang, Feng, op. cit. p. 125 ('́nfasis añadido).

84 Fasslabend, Werner, op. cit., 300.

85 Jinping, Xi, China's President Xi Jinping's Opening Address of G20 Summit: A New Blueprint for Global Economic Growth, Hangzhou, Ministerio de Asuntos Exteriores de la República 
Esta revista forma parte del acervo de la Biblioteca Jurídica Virtual del Instituto de Investigaciones Jurídicas de la UNAM

De acuerdo con Rong Wong, de manera ideal, los proyectos del CYR contarían con las siguientes fases de cooperación entre China y los países interesados en participar: 1) la cooperación será conducida a través de la construcción conjunta de infraestructura con los países a lo largo de las rutas del CYR; 2) se promoverá el desarrollo industrial y la mejora de las condiciones de vida de las comunidades donde se desarrollan los proyectos; 3) se acelerará la liberalización comercial y la facilitación de inversiones en estos países; 4) se promoverá la especialización internacional y la cooperación inter-industrial e intra-industrial; 5) se mejorará la posición relativa de los participantes en la cadena de generación de valor agregado mundial; 6) se promoverá la integración de los participantes a la cadena de suministro, la cadena industrial y las cadenas de valor. ${ }^{86}$

\section{EL CYR Y LA GOBERNANZA DEL SISTEMA MUNDIAL DE COMERCIO}

Desde la década de 1990, China se ha integrado de manera continua a las instituciones multilaterales que regulan a la gobernanza económica mundial (especialmente en el caso de su adhesión a la OMC en 2001). Al igual que los acuerdos megarregionales (TTIP, TPP y UEEA), el CYR es una iniciativa que se rige por los principios normativos de la OMC. Como mencionan Balázs Sárvári y Anna Szeidovitz: "China ha decidido aceptar las regulaciones de la globalización” aunque en un periodo de crisis económica mundial y de "desilusión" por el funcionamiento limitado de algunas de sus estructuras de cooperación (como el G-20); por esta razón, en la actualidad el gobierno chino también aspira a la conformación de sus propias estructuras regulatorias que "contribuyan a la estabilidad" de la gobernanza del comercio mundial. ${ }^{87}$ El CYR y BAII son dos de las iniciativas y estructuras regulatorias propuestas por el gobierno chino en tanto "bienes públicos" que aspiran a

Popular China, 3 de septiembre de 2016, disponible en: http://www.fmprc.gov.cn/mfa_eng/ zxxx_662805/t1396112.shtml (fecha de consulta: 12 de septiembre de 2016).

86 Wang, Rong, "Preface”, en Wang, Rong y Cuiping, Zhu (ed.), Annual Report on the Development of the Indian Ocean Region (2015) 21st Century Maritime Silk Road, Singapur, Springer y Social Sciences Academic Press, 2016, p. xi.

87 Sárvári, Balázs y Szeidovitz, Anna, op. cit. p. 5. 
Esta revista forma parte del acervo de la Biblioteca Jurídica Virtual del Instituto de Investigaciones Jurídicas de la UNAM

cumplir con la nueva función reguladora y contribuyan a la estabilidad del sistema. ${ }^{88}$

El respeto a las instituciones que regulan al sistema mundial de comercio fue enfatizado por el presidente Xi Jinping en el discurso en que presentó el proyecto CYR a los asistentes al Foro Bo' ao para Asia efectuado en 2015; de acuerdo con el discurso oficial, en el contexto de la instrumentación del CYR y sus órganos de financiamiento, el gobierno chino:

Apoya al sistema multilateral de comercio, se enfoca en las negociaciones de la Ronda de Doha, impulsa la creación del área de Libre Comercio de Asia Pacífico, promueve las negociaciones sobre el RCEP, aboga por la creación del Banco Asiático de Inversión en Infraestructura, estimula la cooperación económica y financiera, y trabaja como un promotor activo de la globalización económica y la integración regional. ${ }^{89}$

Desde la perspectiva del gobierno chino debe existir una compatibilidad entre las directivas del CYR y la normatividad de la OMC. Para Zeng Lingliang, la razón de ello reside en dos aspectos: 1) China no planea construir un nuevo mecanismo rector de la gobernanza del comercio internacional que sustituya a la OMC; 2) para facilitar la instrumentación del CYR, China "busca tomar ventaja de los mecanismos de cooperación bilaterales y multilaterales existentes" en el desarrollo de la cooperación regional: entre estos mecanismos se encuentra la OMC. ${ }^{90}$ Asimismo, las reglas de la OMC pueden ofrecer una estructura normativa en el contexto de la diversidad legal existente en el conjunto de países asociados a los proyectos del CYR. ${ }^{91}$ De esta forma, se puede establecer una relación pragmática entre las directivas del CYR y la normatividad de la OMC.

Como señala el documento Visión y Acciones sobre el Cinturón Económico de la Ruta de la Seda y la Ruta de la Seda Marítima del Siglo XXI, sobre la relación

88 Jinping, Xi. "China willing to provide more "Public Goods" to World: Xi”, Xinhua, 9 de noviembre de 2014, disponible en: http://news.xinhuanet.com/english/china/201411/09/c_133776016.htm (fecha de consulta: 10 de junio de 2016).

89 Jinping, Xi, XI Jinping Holds Talks with Representatives of Chinese and Foreign Entreprenours attending BFA Annual Conference, BFA Annual Conference, Bo'ao, 9 de abril de 2015, disponible en http: / / english.boaoforum.org/hynew/19402.jhtml (fecha de consulta: 26 de abril de 2016).

90 Lingliang, Zeng, op. cit. p. 11.

91 Mingkang, Liu y Wenzhi, Lu, op. cit. 
Esta revista forma parte del acervo de la Biblioteca Jurídica Virtual del Instituto de Investigaciones Jurídicas de la UNAM

entre el CYR y la OMC: los países asociados a lo largo del CYR "deben garantizar que el Acuerdo sobre Facilitación del Comercio de la OMC se encuentre en vigor y se aplique". ${ }^{92}$

De acuerdo con Kong Qingjiang y Ping Xiaojuan, tradicionalmente China ha mantenido una actitud "cauta y conservadora" hacia las normas internacionales; sin embargo, su posicionamiento como una gran potencia económica orienta al régimen comunista a participar de manera creciente en las instituciones internacionales: "Debido a la acumulación de poder de China será cuestión de tiempo para que de manera rigurosa promueva normas internacionales con características chinas...". ${ }^{93}$

Igualmente, como indican algunos autores, el objetivo a largo plazo del CYR es crear las condiciones de conectividad e interdependencia para facilitar las negociaciones de un tratado de libre comercio entre los participantes (especialmente entre los ubicados en Eurasia). ${ }^{94}$ Sin embargo, como menciona Zhu Cuiping, el CYR va más allá en comparación con un tratado de libre comercio: “...no es un simple acuerdo para una zona de libre comercio, sino un nuevo mecanismo de cooperación regional que responde a los cambios internos y en el entorno externo de China y también es una nueva plataforma para la diplomacia económica de China en la Nueva Era”. ${ }^{95}$

Por su parte, para Zhao Longyue el CYR resulta diferente a los tratados de libre comercio "convencionales" debido a que no existen barreras para la libre adhesión de los actores al proyecto (careciendo de las exigencias de estandarización de acuerdos como el TPP). El CYR se enfoca en un funcionamiento del libre mercado abierto y flexible (la realización del proyecto

92 Comisión Nacional para el Desarrollo y la Reforma, Ministerio de Asuntos Exteriores y Ministerio de Comercio de China, cit.

93 Qingjiang, Kong y Xiaojuan, Ping, “International Law and International Institutions: Implications for a Rising China”, The Chinese Journal of Global Governance, vol. 1, 2015, p. 163.

94 Fasslabend, Werner, op. cit. p. 296; Yiwei, Wang, “China's "New Silk Road”: A Case Study in EU-China Relations”, en Amighini, Alessia y Berkofsky, Axel (ed.), Xi’s Policy Gambles: The Bumpy Road Ahead, Milán, ISPI-Edizioni Epoké, 2015, p. 95.

95 Cuiping, Zhu, "The Construction Capability, Challenges and the Corresponding Countermeasures of the 21st-Century Maritime Silk Road”, en Wang, Rong y Cuiping, Zhu (ed.), Annual Report on the Development of the Indian Ocean Region (2015) 21st Century Maritime Silk Road, Singapur, Springer y Social Sciences Academic Press, 2016, p. 6. 
Esta revista forma parte del acervo de la Biblioteca Jurídica Virtual del Instituto de Investigaciones Jurídicas de la UNAM

no tiene un límite de tiempo especificado) y busca conformar un nuevo modelo de cooperación internacional. ${ }^{96}$ De acuerdo con Zeng Lingliang:

La integración regional parece ser, hasta cierto punto, el própósito de la Iniciativa.

Esta tiene el objetivo de «promover ordenadamente el libre flujo de los factores económicos», pero parece más ambiciosa que un área de libre comercio... Sin embargo, es menos que un mercado común. ${ }^{97}$

Como sintetizan Sárvári y Szeidovitz: "Los objetivos a corto plazo son de enriquecimiento económico y los objetivos a largo plazo son geopolíticos. Sólo el futuro dirá cómo China utilizará su influencia para impulsar sus intereses". ${ }^{98}$

Por su parte, Zhao identifica algunas características en la modalidad china de un acuerdo de libre comercio en los niveles bilateral y megarregional:

1) El modelo impulsado por China "se enfoca principalmente en las necesidades del desarrollo económico interno". ${ }^{99}$

2) Apertura y flexibilidad. En general, los acuerdos de libre comercio impulsados por China se encuentran en una etapa de negociación para alcanzar arreglos recíprocos teniendo como prioridad a la apertura de los mercados (en aspectos como la reducción y eliminación de las cuotas tarifarias y las facilidades para el comercio y la inversión). De acuerdo con Zhao, la redacción de los términos legales de los acuerdos es "relativamente sencilla": "Los principios subyacentes son: lo simple primero, lo complejo más tarde; firmar primero, mejorar más tarde". ${ }^{100}$

Como señala Heng Wang, los acuerdos de libre comercio negociados por China van acompañados del requerimiento hacia sus interlocutores de que reconozcan a la economía china con el estatus de Economía de Mercado de acuerdo con las normativas de la OMC (en

96 Longyue, Zhao, "China Trade Strategy: FTAs, Mega-Regionals, and the WTO”, RSCAS PP 2015 /11, Florencia, European University Institute, Robert Schuman Centre for Advanced Studies, 2015, p. 3.

97 Lingliang, Zeng, op. cit. p. 7.

98 Sárvári, Balázs y Szeidovitz, Anna, op. cit. p. 7.

99 Longyue, Zhao, op. cit. p. 4.

100 Idem. 
su caso, la UE se ha negado a proporcionar el estatus de Economía de Mercado a China debido al déficit comercial desfavorable que mantiene con Beijing). ${ }^{101}$ Sin embargo, el 11 diciembre de 2016 los miembros de la OMC que no han reconocido a China como una Economía de Mercado, deberán otorgar dicho estatus, según la normativa basada en el Protocolo de Acceso de China a la OMC (una coyuntura que puede crear un escenario favorable para el impulso a los proyectos de integración megarregional de Beijing). ${ }^{102}$

3) Mantenimiento del statu quo. En comparación con los acuerdos de libre comercio megarregionales como el TPP y elTTIP, los acuerdos de libre comercio de China no mantienen el mismo objetivo prioritario hacia "la innovación y el rediseño de las normas que rigen la regulación económica y el comercio”. ${ }^{103}$

Para Zhao, mediante sus proyectos de integración megarregional, China no pretende asumir una posición de liderazgo en la generación de los nuevos marcos regulatorios, sino que "se encuentra más preocupada por la creación de oportunidades de beneficio mutuo" para todos los participantes. La razón para ello es evitar un escenario de competencia entre las potencias con consecuencias negativas para el sistema internacional en general (China prefiere el respeto al statu quo y sus estructuras en lugar de la creación de bloques regionales excluyentes y un escenario de ruptura del sistema de gobernanza del comercio global). ${ }^{104}$ Como señala Wu Jianmin:

...para llevar a cabo la iniciativa Cinturón y Ruta debemos seguir las normas. Estas normas deben ser normas reconocidas internacionalmente y no normas diseñadas por un solo país o "normas ocultas". En el proceso de instrumentar el Cinturón y Ruta debemos insistir en que las normas deben ser aceptadas por todos los países.

101 Wang, Heng, “The Features of China's Recent FTA and Their Implications: An Anatomy of the China-Korea FTA”, Asian Journal of WTO \& International Health Law and Policy, vol. 11, núm. 1, 2016, p. 121.

102 Kok, Jochem de, “The Future of EUTrade Defence Investigations against Imports from China”, Journal of International Economic Law, vol. 19 , núm. 2, 2016, pp. 515-516.

103 Longyue, Zhao, op. cit. p. 4

104 Idem. 
Cualquier cosa que haga China que vaya en contra de las normas internacionales y genere "normas ocultas" debe ser abandonada. ${ }^{105}$

Sin embargo, el respeto al statu quo no significa que China no aspire a influir en la generación de las normas de la nueva gobernanza del comercio global. Un ejemplo de ello es el caso de la exclusión de China del TPP. Desde el discurso del gobierno estadounidense, no existe una necesidad para que China forme parte del TPP puesto que Beijing puede aproximarse al acuerdo al adoptar sus normas y estándares. Como declaró el presidente Obama en 2014:

...han habido algunos comentarios acerca de que al constituir el TPP estamos tratando de contener a China o ponerla en desventaja. En realidad no lo hacemos... lo que esperamos es que China se una a nosotros, sin ser formalmente un miembro del TPP por necesidad, adoptando algunas de las mejores prácticas que aseguren la equidad en la forma de operar. ${ }^{106}$

Sin embargo, para China la posición anterior parece ser inaceptable: en lugar de asumir la normatividad de un acuerdo al que no pertenece, el gobierno chino ha preferido instrumentar un proyecto como el CYR y sus objetivos.

4) Una característica relevante de los acuerdos de libre comercio de China (y sus instrumentos) reside en que permiten la pertenencia múltiple (flexibilidad), por parte de los actores, a una diversidad de instituciones y estructuras; un ejemplo de ello es el BAII, al que pertenecen países miembros de la UE, los cuales al mismo tiempo forman parte de la negociación del TTIP y pertenecen a una alianza de defensa mutua como la Organización del Tratado del Atlántico Norte (OTAN).

105 Jianmin, Wu, "Foreword: The Belt and Road. A Significant Initiative with Profound Impact”, en Wang, Rong y Cuiping, Zhu (ed.), Annual Report on the Development of the Indian Ocean Region (2015) 21st Century Maritime Silk Road, Singapur, Springer y Social Sciences Academic Press, 2016, p. vii.

106 Obama, Barack, Remarks by the President at Meeting of the Export Council, Washington, The White House, Office of the Press Secretary, 11 de diciembre de 2014, disponible en: https: / www.whitehouse.gov/the-press-office/2014/12/11/remarks-president-meeting-export-council (fecha de consulta: 15 de junio de 2015). 
Un caso de la pertenencia múltiple por parte de los actores es Reino Unido, un país que en junio de 2016, por medio de un referéndum (no vinculante), ha decido dejar de ser miembro de la UE y que desde 2015 es miembro fundador del BAII (no obstante la clara oposición del gobierno estadounidense a que Reino Unido se uniera al BAII). ${ }^{107} \mathrm{~A}$ partir de la votación del referéndum para salir de la UE (el denominado Brexit) se presentó la siguiente coyuntura, descrita por el investigador John Saxe-Fernández: "El Brexit deja a Londres en la OTAN, sí, pero fuera de la UE y como socio de un yuan euroasiático". ${ }^{108}$ Cabe mencionar que al dejar de ser miembro de la UE, el gobierno británico podrá negociar los términos de sus relaciones económicas y financieras con China de forma bilateral (como en el caso del mencionado estatus de economía de mercado). ${ }^{109}$

\section{LA PROYECCIÓN GEOPOLÍTICA DEL CINTURÓN ECONÓMICO} DE la Ruta de la SEDA Y la Ruta de la SEDA Marítima DEL Siglo XXI

\section{El Cinturón Económico de la Ruta de la Seda}

El CERS aspira a conformar un área de cooperación regional que abarca desde el Océano Pacífico hasta la Unión Europea cubriendo una variedad de rutas de conectividad de carreteras y ferrocarriles. La lógica de la trayectoria del proyecto de conectividad es este-oeste (y viceversa). Asimismo, la variedad de las rutas tiene una estructura clara: la orientación desde las provincias ubicadas en la costa oriental de China hacia las provincias occidentales como Xinjiang y Tíbet.

107 Watt, Nicholas et al., "US anger at Britain joining Chinese-led Investment Bank AIIB", The Guardian, 13 de marzo de 2015, disponible en: https://www.theguardian.com/usnews $/ 2015 / \mathrm{mar} / 13 /$ white-house-pointedly-asks-uk-to-use-its-voice-as-part-of-chinese-led-bank (fecha de consulta: 30 de junio de 2016).

108 Saxe-Fernández, John, “Geoeconomía y geopolítica del Brexit”, La Jornada, México, 7 de julio de 2016, disponible en: http: / / www.jornada.unam.mx/2016/07/07/opinion/022aleco (fecha de consulta: 7 de julio de 2016).

109 Cheng, Wy, "How China can benefit from Brexit", The Diplomat, 30 de junio de 2016, disponible en: http://thediplomat.com/2016/06/how-china-can-benefit-from-brexit/ (fecha de consulta: 7 de julio de 2016). 
Esta revista forma parte del acervo de la Biblioteca Jurídica Virtual del Instituto de Investigaciones Jurídicas de la UNAM

Las rutas de conectividad en China tendrán a sus puertos ferroviarios y sus centros de distribución de productos en las Zonas de Libre Comercio de reciente creación como Horgos y Kashgar (en Xinjiang) y partir de allí se dirigirán hacia los países de Asia central (como Kazajistán, Kirguistán y Tayikistán) e igualmente hacia los países de la UE: ${ }^{110}$ puede considerarse que las dos regiones más importante del CERS son China y los países europeos.

El tiempo utilizado en la transportación de bienes y personas por vía terrestre a través de los trenes de alta velocidad, desde la costa oriental de China hasta Europa Occidental, sería notablemente menor en comparación con el tiempo utilizado en la actualidad en la transportación por vía marítima: mientras que por mar las mercancías desde China tardan en llegar entre 2.5 a 3 semanas a los puertos europeos, por vía terrestre el tiempo de trasportación podría durar entre 13 a 15 días. ${ }^{111}$ Si bien el costo por la vía terrestre es mayor, dicha vía podrá ser utilizada, preferentemente, para ciertos productos de alto valor agregado (especialmente productos sensibles a los viajes de mayor duración pero inmunes al clima frío de la región euroasiática), lo que haría más competitiva esta opción en comparación a la vía marítima. ${ }^{112}$

En la actualidad existen dos rutas que unen a Asia del Este con Europa: el Ferrocarril Transiberiano y el Nuevo Puente Continental Euroasiático (además de otros dos proyectos en los que se planea la cooperación sino-europea: el Trans-European Transport Networks y la China-Europe Land-Sea Express Line). ${ }^{113}$ El Ferrocarril Transiberiano recorre exclusivamente el territorio

110 Sárvári, Balázs y Szeidovitz, Anna, op. cit. p. 8.

111 Ibidem, p. 9

112 Idem.

113 1) El proyecto Trans-European Transport Networks es coordinado por la UE y consiste en la construcción de infraestructura de comunicaciones en el espacio europeo. Disponible en: http: / / ec.europa.eu/transport/infrastructure/tentec/tentec-portal/site/index_en.htm (fecha de consulta: 8 de julio de 2016).

2) El China-Europe Land-Sea Express Line es un proyecto de construcción de infraestructura de comunicaciones, financiado principalmente por capital chino, para ser desarrollado en algunos países ubicados en Europa Central y Oriental. El proyecto fue propuesto por el gobierno chino en diciembre de 2014, en el contexto de la reunión del grupo 16-1 que se llevó a cabo en Belgrado y fue reiterado en la reunión del mismo grupo efectuada en Suzhou en 2015. El objetivo de este proyecto es la unión de los proyectos del CERS con la RSM-XXI en su convergencia en los Balcanes para una mejor conectividad entre el Sur de Mediterráneo (área a la que pertenece la RSM-XXI) con el resto de Europa. 
Esta revista forma parte del acervo de la Biblioteca Jurídica Virtual del Instituto de Investigaciones Jurídicas de la UNAM

de Rusia entre los puertos de Vladivostok y Rotterdam y no es considerado en la propuesta china de conectividad con la UE.

Por su parte, el Nuevo Puente Continental Euroasiático recorre desde el puerto de Lianyungang, ubicado en la costa oriental de China (en la provincia de Jiangsu), hasta Rotterdam. Para el gobierno chino el Nuevo Puente Continental Euroasiático es la ruta principal en la conectividad entre Asia del Este y Europa, la cual será suplementada por otros corredores de menor extensión, a lo largo de la ruta, con la finalidad de integrar a más áreas a la iniciativa. ${ }^{114}$

En la actualidad existen algunas rutas en operación que conectan a China con Europa para la transportación de bienes: el ferrocarril YuXinOu (es decir, Yiwu-Xinjiang-Europa [Ouzhou]) que se divide en dos recorridos: 1) entre la ciudad industrial de Yiwu hasta Madrid y 2) el recorrido entre Chongqing hacia Duisburgo (Alemania) y que termina en el puerto de Amberes. ${ }^{115}$ También existen otras rutas como el ferrocarril Rongou, que hace un recorrido de 12 días entre Chengdu (Sichuan) y Lodz en Polonia, además del ferrocarril Zhengzhou entre Hamburgo y Zhengzhou (Henan). ${ }^{116}$

A largo plazo, el gobierno chino proyecta construir líneas de alta velocidad que se extiendan desde su costa oriental hacia Reino Unido a través de Kazajistán, Kirguistán, Tayikistán, Uzbekistán, Turkmenistán, Irán, Turquía, Bulgaria, Rumania, Hungría, Austria, Alemania, Francia, Bélgica y España.

Véase Keqiang, Li, “Full text of Chinese Premier Li Keqiang's remarks at the Fourth Summit of China and Central and Eastern European Countries", China Central Television, 25 de noviembre de 2015, disponible en: http://english.cntv.cn/2015/11/25/ART11448450544419961. shtml (fecha de consulta: 4 de Julio de 2016).

114 Xinhua, "Riga Guidelines for Transport between China, CEE Countries Adopted", Xinhua, 17 de mayo de 2016, disponible en: http://news.xinhuanet.com/english/201605/17/c_135366446.htm (fecha de consulta: 10 de junio de 2016).

115 El primer recorrido entreYiwu y Madrid se realizó entre diciembre-enero de 2014 y se realiza en 21 días. Una crítica de la parte europea a la dinámica de las relaciones comerciales entre China y la UE ha sido el déficit comercial que ha beneficiado a la parte china desde finales de la década de 1990. En el caso del ferrocarril YuXinOu, esto se refleja en que llega cargado de productos de China, pero no lleva la misma cantidad de productos en el viaje de regreso a Asia "debido a la asimetría de las relaciones comerciales con China". Carbajosa, Ana, "El tren Madrid-Yiwu circula a medio gas", El País, 20 de marzo de 2016, disponible en: http: / / economia.elpais.com/economia/2016/03/18/actualidad/1458329302_446055.html (fecha de consulta: 12 de junio de 2016).

116 Sárvári, Balázs y Szeidovitz, Anna, op. cit. 9. 
Esta revista forma parte del acervo de la Biblioteca Jurídica Virtual del Instituto de Investigaciones Jurídicas de la UNAM

El proyecto de líneas de alta velocidad tiene un costo estimado de $\$ 125$ mil millones de dólares y puede finalizar entre los años 2020-2025. ${ }^{117}$ El gobierno chino también proyecta construir una línea de alta velocidad en los Balcanes con la intención de unir al Puerto del Pireo en Grecia (adquirido en su totalidad en 2016 por la empresa de capital chino COSCO) con Europa Central. ${ }^{118}$ El Puerto del Pireo es estratégico pues en el mismo convergen el CERS y la RSM-XXI. Con la finalidad de financiar estos proyectos de construcción de infraestructura se creó el Fondo de Cooperación Chinapaíses de Europa Central y Oriental (Fondo China-ECO) en diciembre de 2014, con un capital de $\$ 3$ mil millones de dólares. ${ }^{119}$ Los bancos de capital chino y el fondo China-ECO financiarán los proyectos de infraestructura coordinados por la agenda del Diálogo $16+1$ como el tren de alta velocidad Budapest-Atenas. ${ }^{120}$

117 Idem. También, véase, Xinhua, "Belt and Road Initiative draws China, Europe Closer”, Xinhua, 21 de junio de 2016, disponible en: http://news.xinhuanet.com/english/201606/21/c_135454841.htm (fecha de consulta: 28 de junio de 2016).

118 Smith, Helena, "Chinese Carrier Cosco is Transforming Piraeus-and has Eyes on Thessaloniki”, The Guardian, 19 de junio de 2014, disponible en: https://www.theguardian.com/ world/2014/jun/19/china-piraeus-greece-cosco-thessaloniki-railways (fecha de consulta: 28 de junio de 2016); Reuters, "Piraeus Port shareholders approve COSCO Concession Deal", Reuters, 10 de junio de 2016, disponible en: http: / / www.reuters.com/article/us-eurozone-greeceprivatisation-protest-idUSKCNOYWOON (fecha de consulta: 28 de junio de 2016).

119 Reuters, “China sees new \$3 Billion Investment Fund for Central and Eastern Europe”, Reuters, 16 de diciembre de 2014, disponible en: http: / / uk.reuters.com/article/uk-europe-chinaeast-idUKKBNOJU22920141216 (fecha de consulta: 10 de junio de 2016).

120 En noviembre de 2013, los gobiernos de China, Hungría y Serbia firmaron un memorándum de entendimiento para la construcción de un tren de alta velocidad que cubrirá la ruta Belgrado-Budapest financiado con capital chino. La construcción del tren comenzó en 2015 y se proyecta que concluya en 2017; el tren tendrá un costo de \$2,500 millones de dólares y será financiado por el Export-Import Bank of China, la compañía constructora responsable del proyecto es la China Railway and Construction Corporation de capital estatal. El objetivo es extender la línea férrea del tren de alta velocidad desde Belgrado hasta Atenas que cubrirá la ruta Belgrado-Skopje (Macedonia)-Atenas con la finalidad de crear una infraestructura de comunicación favorable para el transporte de bienes desde el Puerto del Pireo hacia Europa central.

Véase: Pavlićević, Dragan, "China's Railway Diplomacy in the Balkans”, China Brief vol. 14, núm. 20, 2014, p. 8; Xinhua, "A Panorama of China-CEE Cooperation under Belt and Road Initiative”, Xinhua, 27 de marzo de 2016, disponible en: http://news.xinhuanet.com/ english/2016-03/27/c_135227003.htm (fecha de consulta: 10 de junio de 2016). 
Esta revista forma parte del acervo de la Biblioteca Jurídica Virtual del Instituto de Investigaciones Jurídicas de la UNAM

\section{La Ruta de la Seda Marítima del Siglo XXI}

Por su parte, la actual RSM-XXI-CYR tiene la prioridad de orientarse en dos vertientes: 1) desde las provincias ubicadas en el sur de China (comoTíbet, Yunnan y Guangxi) hacia el Sur de Asia, Myanmar y el Océano Índico y 2) desde las provincias ubicadas en la costa oriental de China hacia el Mar del Sur de China, el Estrecho de Malaca alcanzando los países costeros ubicados en el Océano Índico (Golfo Pérsico, Mar Rojo y el Golfo de Adén), incluyendo la costa de África y la costa del Sur del Mediterráneo. La RSMXXI concluye en el Puerto del Pireo en Grecia en donde converge con el CERS. ${ }^{121}$ Debe mencionarse que todo el continente africano se encuentra incorporado en los proyectos del CYR incluyendo los países ubicados en su costa atlántica.

\section{EL CYR ¿UN BIEN PÚBLICO GLOBAL?}

De acuerdo con la retórica oficial, China puede mostrarse como un poder responsable mediante la instrumentación del CYR, pero sin abandonar los principios doctrinales de su política exterior. ${ }^{122}$ En este sentido, el CYR es justificado como un "bien público" proporcionado por China para los miembros del sistema internacional en coherencia con sus Cinco Principios de Coexistencia Pacífica. ${ }^{123}$ De acuerdo con el Ministro de Asuntos Exteriores, Wang Yi, el CYR: “...es una respuesta a la necesidad de desarrollo y la cooperación entre los países de Asia y Europa, y muestra que China está en una transición rápida de ser un simple participante en el sistema internacional

121 Wang, Rong, op. cit., pp. x y xi.

122 En los principios doctrinales de salvaguarda de su soberanía y la integridad territorial se encuentran las limitantes por parte del gobierno chino a la aceptación o no de las normas internacionales. Un ejemplo negativo es el rechazo de Beijing al fallo emitido en julio de 2016 por la Corte Permanente de Arbitraje de La Haya en relación con el conflicto territorial sino-filipino en el Mar del Sur de China. Dicho arbitraje fue desfavorable a China. Wang Yi. “Arbitraje sobre Mar Meridional de China, farsa política: Canciller chino”, Diario del Pueblo, 13 de julio de 2016, disponible en: http: / /spanish.peopledaily.com.cn/n3/2016/0713/c316219085220.html (fecha de consulta: 13 de julio de 2016).

123 Jianmin, $\mathrm{Wu}$, op. cit., p. vii. 
Esta revista forma parte del acervo de la Biblioteca Jurídica Virtual del Instituto de Investigaciones Jurídicas de la UNAM

a ser un proveedor de bienes públicos". ${ }^{124}$ La generación de un bien público como el CYR, por parte de China, se deriva de su intención de no ser excluida en la generación de las nuevas normativas del comercio internacional. ${ }^{125}$

Como menciona Eduardo Tzili, la proporción de un bien público, por parte de un actor internacional, es una expresión de su poder blando; estos bienes públicos globales pueden ser de cinco tipos: medio ambiente, salud, conocimiento, seguridad y gobernanza. ${ }^{126}$ En el caso del CYR, el gobierno chino ha presentado un proyecto de integración megarregional (en tanto bien público global) que busca posicionar a China en la definición de las normativas del comercio internacional, aunque manteniendo a Beijing como participante de las estructuras de la gobernanza del comercio global (como la OMC).

En la coyuntura actual, el gobierno chino no desea una modificación estructural de dichas normas o, menos, romper con el sistema de gobernanza. Además, como mencionan Kong Qingjiang y Ping Xiaojuan, en general China se ha mostrado respetuosa de las normativas de la OMC y "ha mostrado su satisfacción con el Mecanismo de Resolución de Diferencias de la OMC en tanto que es un órgano resolutivo para las disputas entre los Estados". ${ }^{127}$ Sin embargo, como se ha mencionado, los límites de la coincidencia entre los intereses de China con su respeto hacia las normas internacionales residen en la defensa de los principios doctrinales de su política exterior. Esto significa que los principales riegos para la instrumentación del CYR se relacionan con los conflictos territoriales que mantiene Beijing con sus vecinos en el Mar del Sur de China, el conflicto territorial con Japón y la cuestión de Taiwán (especialmente tras el inicio del periodo de gobierno de Tsai Ing-wen a partir de mayo de 2016).

124 Yi, Wang, "China's Belt and Road Initiative not Expansionism: FM", Xinhua, 8 de marzo de 2016, disponible en: http://english.gov.cn/news/top_news/2016/03/08/content_281475303585446.htm (fecha de consulta: 30 de junio de 2016).

125 Como señala Wang Yi: “China se esfuerza para construir un nuevo tipo de relación con los demás países de acuerdo con los Cinco Principios de Coexistencia Pacífica teniendo como base al derecho internacional".

Véase Yi, Wang, "China: a Staunch Defender and Builder of the International Rule of Law", Chinese Journal of International Law, vol. 13, núm. 4, pp. 635 y 636; Sárvári, Balázs y Szeidovitz, Anna, op. cit. p. 5.

126 Tzili Apango, Eduardo, “China y la provisión de bienes públicos globales. Falacia sobre el ascenso hegemónico”, México y la Cuenca del Pacífico, mayo-agosto de 2012, p. 80.

127 Qingjiang, Kong y Xiaojuan, Ping, op. cit., p. 172. 
Esta revista forma parte del acervo de la Biblioteca Jurídica Virtual del Instituto de Investigaciones Jurídicas de la UNAM

\section{CONSIDERACIÓN FINAL}

En la investigación se ha descrito cómo la Iniciativa CYR es el proyecto de desarrollo hacia exterior de mayor relevancia para el gobierno de Xi Jinping. En el CYR convergen las principales prioridades del gobierno chino tanto en lo referente a sus proyectos de reforma económica interna como en las relaciones de cooperación que aspira a mantener con sus países vecinos en los próximos años (y más allá considerando la importancia de la UE para el CYR). A su vez, la iniciativa coincide con un momento en que el gobierno chino realiza una mayor afirmación de los principios doctrinales de su política exterior, en especial los relacionados con la defensa de su soberanía y lo que percibe como la salvaguarda de su integridad territorial.

El CYR es un mecanismo de cooperación regional con cuatro características básicas: 1) la flexibilidad que posee para incorporar a nuevos actores interesados en participar en sus proyectos de cooperación económica (lejos de los requerimientos y estándares de otros tratados); 2) en el aspecto geopolítico, el alcance transcontinental de los proyectos; 3) en el aspecto institucional, el CYR se apoya en estructuras y plataformas existentes (como la $\mathrm{OMC}$ y las asociaciones estratégicas) para respaldar a las directivas del proyecto: un caso claro es la relación pragmática que busca establecer el CYR con la normatividad de la OMC (hasta el momento); en el aspecto de la gobernanza del sistema mundial de comercio, el CYR puede representar un nuevo modelo para iniciar procesos de liberación comercial conforme aumenta la interdependencia entre una diversidad de actores internacionales.

Aunque se encuentra en una etapa inicial, es claro que el CYR puede representar un nuevo modelo de gobernanza con consecuencias geopolíticas y geoeconómicas relevantes para el sistema internacional y para el sistema mundial de comercio en particular.

\section{BibLIOGRAFÍA MÍNIMA}

BouZas, Roberto y ZeliCOviCH, Julieta, "La Organización Mundial de Comercio, los acuerdos mega-regionales y los usos estratégicos del regionalismo", Estudios de Economía Aplicada, vol. 32, núm. 3, 2014. 
Connelly, Marisela, Historia de Taiwan, México, El Colegio de México, 2014.

Feng, Zhang, "China as a Global Force", Asia \& the Pacific Policy Studies, vol. 3, núm. 1, 2016.

QIngJiAng, Kong y XiaOjuan, Ping, "International Law and International Institutions: Implications for a Rising China”, The Chinese Journal of Global Governance, vol. 1, 2015.

LingLiAnG, Zeng, "Conceptual Analysis of China's Belt and Road Initiative: A Road towards a Regional Community of Common Destiny”, Chinese Journal of International Law, agosto, 2016.

LONGYUE, Zhao, "China Trade Strategy: FTAs, Mega-Regionals, and the WTO”, RSCAS PP 2015/11, Florencia, European University Institute, Robert Schuman Centre for Advanced Studies, 2015.

SÁRVÁRI, Balázs y SzeIdovitz, Anna, "The Political Economics of the New Silk Road”, Baltic Journal of European Studies, vol. 6, núm. 1, 2016. 